\title{
Multi-Objective Optimal Model for Sustainable Management of Groundwater Resources in an Arid and Semi-arid Area Using a Coupled Optimization- Simulation Modeling
}

mahmoud mohammad rezapour tabari ( $\Delta$ mrtabari57@gmail.com )

University of Mazandaran https://orcid.org/0000-0002-4837-5026

Mehdi Eilbeigi

Shahid Chamran University of Ahvaz

Manouchehr chitsazan

Shahid Chamran University of Ahvaz

\section{Research Article}

Keywords: Karaj aquifer, Nitrate concentration, GMS simulation model, NSGA-II, Multi-objective optimization, Sustainable development, MATLAB code

Posted Date: June 21st, 2021

DOl: https://doi.org/10.21203/rs.3.rs-599210/v1

License: (c) (1) This work is licensed under a Creative Commons Attribution 4.0 International License.

Read Full License 


\title{
Multi-Objective Optimal Model for Sustainable Management of Groundwater Resources in an Arid and Semi-arid Area Using a Coupled Optimization-Simulation Modeling
}

\author{
Mahmoud Mohammad Rezapour Tabari ${ }^{1}$, Mehdi Eilbeigi' ${ }^{2}$, Manouchehr chitsazan ${ }^{3}$ \\ ${ }^{1}$ Associate Prof., Dep, of Civil Engineering, Faculty of Technology and Engineering, University of Mazandaran, \\ Babolsar, Telephone: (+98) (11) 35305133, E-mail: mrtabari@umz.ac.ir (Corresponding Author) \\ ${ }^{1}$ Center of Excellence in Risk Management and Natural Hazards, Isfahan University and Technology, Isfahan, Iran \\ ${ }^{2} \mathrm{Ph} . \mathrm{D}$ in Hydrogeology, Dep. of Hydrogeology, Shahid Chamran University, Ahvaz, Iran, E-mail: m- \\ eilbeigy@phdstu.scu.ac.ir \\ 3Prof., Dep. of Hydrogeology, Shahid Chamran University, Ahvaz, Iran, E-mail: chitsazan_m@scu.ac.ir
}

\section{Abstract}

Increased abstraction from the aquifer, in addition to the progressive drawdown of groundwater table can increase the concentration of pollutants. This research, optimal scenario for withdrawing water from wells is proposed for the aquifer sustainable development. The aquifer quantitative and qualitative simulation was carried out with the GMS model. The developed code in MATLAB2018b provides the link between the simulation and the NSGA-II optimization tools. Optimal scenario was chosen based on applying the Multiple-Criteria Decision Making (MCDM) and Berda Aggregation Method (BAM). The results show that reducing the current withdrawal rate to $51.55 \%$ can establish the quantitative and qualitative stability of the aquifer. The spatial and temporal distribution of nitrate concentration after applying the optimal discharge of wells shows that the nitrate concentration in central and eastern parts of the aquifer have greatly reduced. The developed structure can be used to improve the quantitative and qualitative status of any aquifer. Keywords: Karaj aquifer, Nitrate concentration, GMS simulation model, NSGA-II, Multiobjective optimization, Sustainable development, MATLAB code 


\section{Introduction}

27 Groundwater resources are one of the main and most important components of water supply in the domestic, agricultural, and industrial sectors. Lack of precipitation, high potential of evapotranspiration, increasing consumption along with their development during the past decades have caused an increasing pressure on water resources, especially groundwater resources in arid

31 and semiarid regions (Safavi et al., 2010).

In Iran, more than 300 plains out of 609 plains in this country due to intensive use of groundwater have been declared as "forbidden plains". In these plains, with extensive withdrawals and over water capacity from aquifers, these underground reservoirs face a negative water balance of nearly 5 MCM (Million Cubic Meters) per year. A total of 500 BCM (Billion Cubic Meters) of strategic underground reservoirs have been identified in Iran. Of this amount, 200 BCM is brackish water and only $300 \mathrm{BCM}$ in terms of quality can be used by various consumer sectors. So far, for various reasons, significant amounts of these resources of more than $110 \mathrm{BCM}$ (more than $36 \%$ of static exploitation permission has led to significant decrease well yields, decrease in GWTL, reduction in groundwater discharge to streams, increase in pumping costs, decrease in groundwater quality, land subsidence in a number of plains (Rejani et al., 2009; Zhang et al., 2014; Xiang et al., 2020).

44 It is not possible to create sustainability in quantitative and qualitative conditions of groundwater resources in many arid and semi-arid regions, but it is possible to minimize the adverse effects of over-abstraction by using appropriate operation policies for these valuable water resources.

47 For this purpose, many studies have been proposed and successfully applied to real-world 48 groundwater systems since the 1970 s to manage groundwater resources and create sustainable 
conditions using simulation and optimization tools. In these models, due to the lack of access to important quality parameters such as nitrate and the complexities of aquifer quality modeling, the water quality of the aquifer is usually less considered in development of operation polices of groundwater. Typically, these models use an aquifer simulation model (which can be an analytical solution or well-known codes such as MODFLOW) and an optimization tool to solve groundwater resource management problems. Also, in these studies, optimization tools are different according to the number of decision variables, the complexity of the problem, and the number of objectives. By implementing these groundwater management models, it is possible to provide scenarios of aquifer operation (Ahlfeld and Pinder (1992); Ebraheem et al., 2003; Karamouz et al., 2005; Karamouz et al., 2007; Ayvaz and Karahan (2008); Esteban and Dina (2013); Farhadi et al., 2016; Banihabib et al., 2019; Nazari and Ahmadi (2019); Sabzzadeh and Shourian (2020); Norouzi Khatiri et al., 2020). In this section, as an example, the approaches considered for groundwater management by some researchers are mentioned.

Rejani et al. (2009) proposed a non-linear transient hydraulic management model (model 1) and a linear land allocation optimization model (model 2) for the Balasore coastal basin groundwater 
72 A GA based simulation-optimization model was presented by Sedki and Ouazar (2011). In

73 developed model, the optimal groundwater exploitation strategies in Rhis-Nekor Plain with the

74 objective of maximizing groundwater withdrawals to supply water demands has been considered.

75 This study shows that the proposed pumping strategy can capture an important amount of the

76 nonbeneficial fresh water discharging to the sea for local water supply.

77 Majumder and Eldho (2016) examined the effectiveness of cat swarm optimization (CSO) for 78 groundwater management using the combination of the analytic element method (AEM) and 79 reverse particle tracking (RPT). In this study, three single-objective problems were considered 80 where the objectives are defined as: maximization of the total pumping of groundwater from the 81 aquifer, minimization of the total pumping costs, and minimization of groundwater contamination 82 by capture zone management. The results obtained from applying the developed model to a two 83 hypothetical case study show the superiority of CSO in comparison with other optimization 84 algorithms.

85 A linkage between DSSAT, an agronomic model, and MODFLOW on an annual time step in order to assessing groundwater conservation strategies in groundwater-irrigated regions was prepared

87 by Xiang et al. (2020). Due to the significant increase in aquifer recharge by municipal and 88 agricultural wastewaters, one of the parameters that usually increases in groundwater and has 89 adverse effects on humans is nitrate. This parameter enters the water sources through different 90 ways such as contact of water sources with sewage or discharge of agricultural return flow into the 91 river and most importantly oxidation of nitrogenous organic materials such as proteins. Therefore, 92 it is necessary to pay attention to the simulation of this parameter and provide solutions and policies 93 to improve the quality of groundwater resources in the development of aquifer management 
94 models. The concept of optimal use of groundwater resources, considering the development of

95 nitrate pollution, is a relatively new concept that has received less attention.

96 Ayvaz (2010) introduced a linked simulation-optimization model to determine the source

97 locations and release histories together with the potential source numbers. In the proposed model,

98 MODFLOW and MT3DMS packages were used to simulate the process of flow and transfer of

99 groundwater; then, they integrated the models with the optimization model based on the heuristic

100 harmony search. The results of this study show that the prepared model can be used to solve the

101 inverse pollution source identification problems.

102 Peña-Haro et al. (2011) presented a structure based on nonlinear programming and groundwater

103 flow and mass transport numerical simulation for stochastic optimization of control strategies for

104 groundwater nitrate pollution from agriculture under hydraulic conductivity uncertainty. The

105 research of this study shows that a stochastic analysis allows providing more reliable groundwater

106 management strategies than deterministic models.

107 Alizadeh et al. (2017) developed a fuzzy multi-objective compromise methodology based on

108 MODFLOW and MT3D simulation models, NSGA-II, and Fuzzy Transformation Method (FTM)

109 in order to determine the socio-optimal and sustainable policies for hydro-environmental

110 management of kavar-Maharloo aquifer. The results indicate the proper performance of the

111 proposed model for determining the most sustainable allocation policy in groundwater resource

112 management.

113 For quantitative and qualitative modeling of groundwater systems and their simulation within

114 water resources management optimization models, it is necessary to establish the link between the

115 simulation model and the optimization in a desirable way. In previous studies, due to the software

116 limitations of developed groundwater simulation models such as GMS in accessing their input and 
117 output files, the following approaches for using the results of the aquifer simulation model was

118 used in the optimization process: response matrix method (Rejani et al., 2009; Pena-Haro et al., 119 2009; Pena-Haro et al., 2011; Salcedo-Sa'nchez et al. 2013; Tabari and Soltani, 2013; Tabari and 120 Yazdi, 2014; Rashid et al., 2014, and etc.), using analytic element models to simulate an aquifer 121 under limited and special conditions (Gaur et al., 2011; Majumder and Eldho, 2016, and etc.), use 122 meta-models to communicate between simulation and optimization models (Rogers and Dowla, 123 1994; Karamouz et al., 2007; Tabari, 2015; Alizadeh et al., 2017), create or modify MODFLOW 124 and MT3DMS codes (Wang and Zheng, 1994; GAD and Khalaf, 2013; Elci and Tamer Ayvaz, 125 2014; Sreekanth et al., 2015; Luo et al., 2016; Ayvaz, 2016; Ghaseminejad and Shourian, 2019; 126 Norouzi Khatiri et al., 2020 , and etc.).

127 Review of the previous studies on optimal quantitative and qualitative management of 128 groundwater resources indicated that in the developed models, the use of an aquifer distributed 129 simulation model instead of using simplified relationships to simulate quantitative and qualitative 130 parameters is essential to better description the behavior of groundwater resources. Also, adopting 131 management strategies in the abstraction of the aquifer and its control can be very effective in 132 improving the quantitative and qualitative conditions of the aquifer. Accordingly, in this study, 133 with the aim of achieving sustainable development in the quantitative and qualitative operation of 134 the Karaj plain aquifer, the multi-objective management model was developed based on the GMS 135 simulation model and the NSGA-II multi-objective algorithm. In this model, the accuracy of 136 quantitative and qualitative aquifer simulation has direct effects on the results of the optimization 137 model. Therefore, by preparing code in MATLAB environment for direct connection of the multi138 objective optimization model with the GMS simulation model by direct access to the input and 139 output files of this simulation model, the aquifer was simulated and calibrated as a cell by cell. 
140 It should be noted that the development of a multi-objective quantitative and qualitative model of

141 the aquifer to provide optimal operation policy for each active well and to determine the monthly

142 harvesting from them using the extensive groundwater simulation model is considered as one of

143 the innovative aspects of this study. Also, controlling the concentration of nitrate quality parameter

144 in the developed management model is another new aspect of this study, which has been

145 considered simultaneously with the quantitative management of the aquifer (preventing the

146 progressive drawdown in GWTL and excessive withdrawals). The results obtained from the

147 implementation of the proposed approach show the high performance of aquifer operation policies

148 in order to create quantitative and qualitative sustainability during a short-term planning period.

149 Therefore, applying the proposed approach in other aquifers can reduce the operating costs of

150 groundwater and compensate the water depletion of groundwater. and provide the sustainable and

151 stable operation of aquifers.

152

1532 Materials and methods

$154 \quad 2.1$ Study area

155 Due to the importance of studying critical areas with special political, social and regional 156 sensitivities, in this study, the aquifer of Karaj plain has been selected as case study. This region 157 needs special attention in meeting water supply and controlling groundwater pollution due to its 158 strategic location (Fig. 1).

159 The Karaj plain has experienced a large population density in recent year due to its proximity to 160 the capital of IRAN, Tehran. This has led to an increase in abstraction from groundwater resources 161 and as a result a significant decline in GWTL and decrease in water quality of the Karaj plain 162 aquifer. It should be noted that this region is the biggest destination of immigration in Iran after 
163 Tehran city. The area of case study is 255 square kilometers and is located in the aquifer of Karaj 164 plain with an average altitude of 1274.14 meters above sea level and 48 kilometers northwest of 165 Tehran. The hydrogeological and hydrogeochemical characteristics of case study are fully 166 described in the paper of Chitsazan et al. (2017).

167 In order to investigate the quantitative and qualitative behavior of the aquifer of Karaj plain, it is 168 necessary to first prepare an aquifer simulation model and then be calibrated and validated. The 169 time period considered for aquifer modeling is the 2010-2011 water year. The reason for choosing 170 this water year is the completeness of aquifer hydrogeological and hydrogeochemical data. It 171 should be noted that for quantitative and qualitative modeling of the Karaj plain aquifer under 172 steady and unsteady conditions, quantitative and qualitative data related to the 2010-2011 and 173 2011-2013 water years has been used for calibration and verification, respectively.

174 In qualitative modeling of Karaj plain aquifer, due to the significant growth and development of 175 urban and agricultural land use in this region, the nitrate parameter has been considered as one of 176 the important and effective parameters in the qualitative degradation of groundwater resources. 177 Spatial and temporal distribution of measured nitrate concentration in drinking wells located in the 178 study area over a 14-year period (2000-2013) are presented in the paper of Chitsazan et al. (2017). 


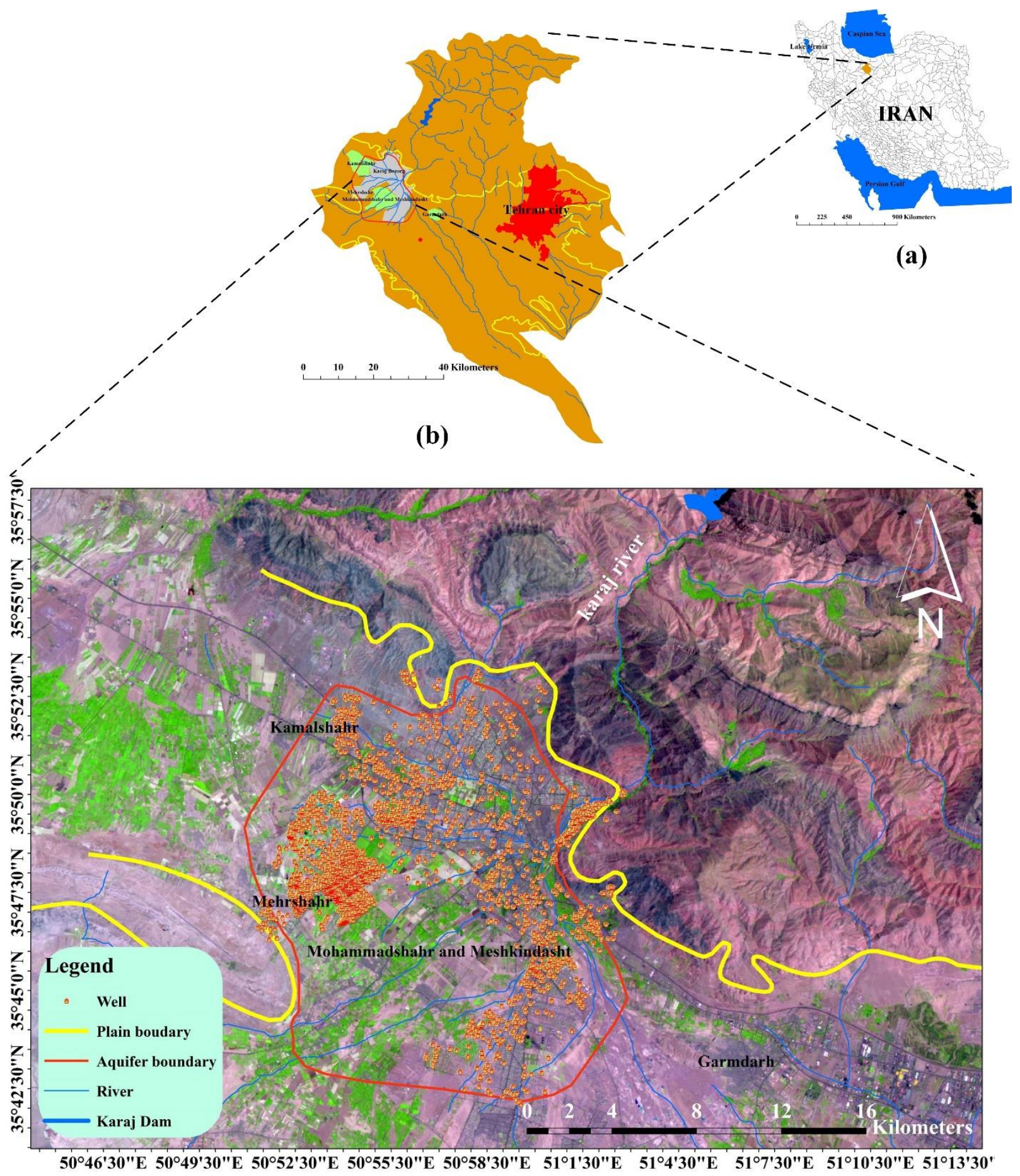

(c)

180 Fig. 1 a) Study areas of aquifers in Iran b) The field application site at Tehran-Karaj plain c) 


\subsection{The structure of the proposed approach}

184 Preparation and development of groundwater resources operation scenarios for sustainable 185 groundwater abstraction and its quality improvement requires the definition of specific 186 management objectives. For this purpose, in this study, a novel approach based on the most 187 appropriate simulation and optimization tools was developed. In this approach, it is first necessary 188 to properly define the objective functions and constraints, and introduce them to the developed 189 model. In this study, three objective functions are considered, which are: minimize the sum of 190 drawdown of GWTL in drinking wells located in the study area during horizon planning (as first 191 objective function), minimize the sum of nitrate concentration in cells containing operation wells 192 during horizon planning (as second objective function) and minimize the sum of withdrawal rate

193 from wells during horizon planning (as third objective function). Due to the nonlinear and complex 194 relationship between groundwater level drawdown, harvesting from aquifer, and nitrate 195 concentration in each of the active aquifer cells, the mentioned goals do not work in the same 196 direction and are considered as conflict objectives.

197 A remarkable point in the proposed approach is the use of the distributed GMS model to simulate 198 the quantitative and qualitative behavior of groundwater in Karaj plain, which unlike lump models, 199 leads to an increase in the accuracy in calculating the GWTL and nitrate concentration parameters.

200 The mathematical form of the objective functions and constraints are defined as follows:

201 Objective function:

$202 \quad$ Minimize $Z_{1}=\sum_{t=1}^{m} \sum_{z=1}^{\text {nwell }} \Delta H_{\mathrm{tz}}$

$203 \quad$ Minimize $Z_{2}=\sum_{t=1}^{m} \sum_{z=1}^{\text {nwell }}$ W well $_{\mathrm{tz}}$

$204 \quad$ Minimize $Z_{3}=\sum_{t=1}^{m} \sum_{z=1}^{\text {nwell }} Q$ well $\mathrm{tz}$

205 Constraints: 
Qwell $_{\mathrm{tz}} \leq$ QCwell $\mathrm{tz}, \quad z=1,2, \ldots$, nwell $, \quad t=1,2, \ldots, m$

208

$\Delta H_{\mathrm{tz}}=H_{t z}-H_{(t-1) z}$

209

$H_{t z}=f\left(Q w_{e l l}, R_{t}, H_{(t-1) z}\right)$

210

Cwell $_{\mathrm{tz}}=g\left(Q\right.$ well $\left._{\mathrm{tz}}, R_{t}, H_{(t-1) z}, \operatorname{Cwell}_{(t-1) z}\right)$

211 Qwell $_{\mathrm{tz}} \geq 0, \quad z=1,2, \ldots$, nwell, $\quad t=1,2, \ldots, m$

212 Cwell $_{\mathrm{tz}} \geq 0, \quad z=1,2, \ldots$, nwell, $\quad t=1,2, \ldots, m$

$213 H_{\mathrm{tz}}>0 \quad, \quad z=1,2, \ldots$, nwell $, \quad t=1,2, \ldots, m$

214 where,

$215 \Delta H_{\mathrm{tz}}$ : The rate of GWTL drawdown associated with well $z$ in month $t(\mathrm{~m})$

$216 Q$ well $_{\mathrm{tz}}$ : Amount of water withdrawn from well $z$ in month $t\left(\mathrm{~m}^{3} /\right.$ day) (as decision variable)

$217 Q$ Q well $_{\mathrm{tz}}$ : Current status of withdrawal from well $z$ in month $t\left(\mathrm{~m}^{3} /\right.$ day)

$218 R_{t}$ : The amount of natural recharge of the aquifer in month $t(\mathrm{~m} /$ day $)$

219 Cwell $_{\mathrm{tz}}$ : Simulated nitrate concentration in well $\mathrm{z}$ and in month $t(\mathrm{mg} / \mathrm{l})$

$220 \quad H_{\mathrm{tz}}:$ Simulated GWTL in well $z$ and in month $t(\mathrm{~m})$

$221 f$ : A function based on which the quantitative behavior of aquifer (based on GWTL parameter) is 222 modeled.

$223 g$ : A function based on which the qualitative behavior of aquifer (based on nitrate parameter) is 224 modeled.

225 nwell: Number of wells in the study area

$226 m$ : Number of months in planning horizon 
In this part, introduced equations will be explained. In equation (1), which is the first objective

229 function, the control of GWTL drawdown (equation (5)) in each well is considered. Based on this

230 relationship, it is necessary to first simulate the GWTL time series using a validated aquifer model.

231 In order to simulate the GWTL, the GMS model is used which is presented in the form of equation

232 (6). This model is as a graphical user interface for MODFLOW simulation model. In fact, for each

233 of the solutions that provided by the optimization algorithm, it is necessary to run an aquifer

234 simulation model to determine the GWTL and its drawdown in each of the simulated cells. Based

235 on equation (6), it can be seen that the parameters of recharge, discharge and GWTL of the

236 previous month are needed as input to simulate the quantitative behavior of the aquifer in GMS

237 model.

238 According to the mentioned explanations above can be found that the satisfaction of the first

239 objective function can be effective in controlling the monthly GWTL drawdown in operation

240 wells, reducing pumping costs, and improving the water quality of the aquifer in the long-term

241 with increasing the saturated thickness of the aquifer. In other words, the first objective function

242 plays an effective role in controlling the quantitative stability of the aquifer.

243 In equation (2), the second objective function of the proposed approach is realized, which is to

244 reduce the nitrate concentration in the operation wells. In order to determine the nitrate

245 concentration in each of the wells, it is necessary to run a calibrated qualitative model, which in

246 this study is MT3DMS and is one of the packages of the GMS model, for different situations of

247 well extraction. This value, which is determined based on equation (7), indicates the qualitative

248 behavior of aquifer in the face of stresses due to water abstraction. In Karaj aquifer, the

249 concentration of nitrate has increased to more than the permissible values due to the remarkable

250 withdrawal by wells. Therefore, this groundwater overdraft was controlled by equation (4). 
251 The third objective function of this study, which plays an important role in the quantitative and 252 qualitative stability of the aquifer, is to minimize the amount of abstraction from operation wells.

253 Indeed, in this objective function (equation (3)), the water supply demands of the region are not 254 considered and long-term operation of the aquifer and attention to the stability of the aquifer in 255 order to improve the water quality of the aquifer are considered as the priority of water withdrawal 256 from wells.

257 Using these three objective functions, which are also complementary to the sustainable 258 development of the aquifer, can be determine the optimal allocation values from each of the wells. 259 Also, based on optimal allocation water can be provided necessary planning to water supply the 260 shortage of demands from other water resources (such as surface water resources).

261 In order to solve the developed management model, initially, it is necessary to define the problem 262 variables which are known as decision variables or unknowns of the model. In this study, the 263 decision variables considered for each month are the monthly amount of water extracted from 264 existing wells. As there are 2453 active operating wells in the Karaj plain, the total number of 265 decision variables will be 58872 within three years planning horizon.

266 The reason for considering each of the exploitation wells as a decision variable is the independence 267 in their exploitation, which is mainly managed by the private sector and it is not possible to 268 integrate them regionally. In fact, in case of aggregation and determination of the optimal amount 269 of water allocation, the optimal amount cannot be properly distributed among the stakeholders.

270 Also, reducing the number of wells and presenting it in the form of a limited number of wells to 271 apply to the distributed model of the aquifer due to not applying the exact position of the harvest, 272 it can lead to errors in simulating the quantitative and qualitative behavior of the aquifer. It should 273 be noted that this approach can be very effective in developing optimal allocation guidelines from 
274 each well for inclusion in the exploitation license and provide appropriate guidance to decision-

275 makers in this area.

276 In this study, a short-term planning horizon (three-year) was considered in order to extract the best

277 polices for operation of wells. Providing optimal aquifer operating policies for a long-term period

278 is not practical for reasons such as changing exploitation approaches as a result of the managerial

279 instability in the organizations in charge of the operation of Iranian aquifers and lack of adequate

280 monitoring of aquifer resources.

281 To determine the optimal amount of these decision variables, we used the NSGA-II that is one of

282 the most suitable optimization tools. According to this multi-objective optimization algorithm,

283 first, an initial population of random values of water withdrawal from each well (as set of solutions)

284 is generated. Then, the values of the objective functions are calculated for each of the solutions.

285 Using the operators defined in the NSGA-II algorithm, the generated solutions are improved

286 during successive iterations to satisfy the developed objective functions. This process continues

287 until there is no change in the optimal trade-off curve. Under these conditions, it can be stated with

288 great probability that the value provided for the decision variables is near to global optimal and

289 can be used as scenarios for the exploitation of wells in the study area. Based on these optimal

290 allocation amounts from different wells, can be formulated the optimal operation policies on a

291 monthly or seasonal basis. To study the NSGA-II algorithm further, one can refer to Tabari and

292 Soltani (2013) article.

293 Figure 2 shows the flowchart to achieve optimal trade-off between objective function and how to 294 extract an aquifer operation policy based on the proposed methodology. According to this figure, 295 to achieve the goals of this study, which is the sustainable qualitative and quantitative groundwater 296 development during planning horizon, a structure based on the hybrid of GMS simulation model 
and the NSGA-II multi-objective optimization algorithm are proposed. Initially, in this structure,

298 the quantitative and qualitative data sets of the studied aquifer (Karaj plain) are collected and 299 monitored.

300 Then, the quantitative and qualitative simulation models of groundwater based on GMS tools were 301 prepared and calibrated. Considering that the inputs GMS simulation model can be called from 302 GIS (Geographic Information System) software, therefore, the digital aquifer layers such as the 303 topography, bedrock, piezometric head, wells data, aquifer hydrodynamic coefficients, land use, 304 the hygrometry and meteorology stations data, location of qualitative measuring points for nitrate 305 concentration, and etc. were prepared in GIS environment and introduced to GMS model.

306 Since the proper simulation of the quantitative and qualitative behavior of the aquifer in the 307 optimization process and the determination of the optimal values of the decision variables is of 308 great importance, therefore, to increase the precision of the aquifer simulation results, a code that 309 can be used to simulate the fully distributed of aquifer within the optimization model was prepared 310 in the MATLAB2018b application environment. This code has the ability to call all input and 311 output files of GMS software in MATLAB environment and is able to quantitative and qualitative 312 modeling of aquifer for a short time (approximately 4 seconds) during a period of 24 months.

313 In developed MATLAB code, the user will be able to change the status of the stresses in the 314 groundwater system (like recharge and discharge) using a file with the h5 extension in the GMS 315 model and observe variation in GWTL and nitrate concentration after the implementation of GMS 316 model. In this code, it is necessary to use a calibrated simulation model of aquifer, which indicates 317 the actual behavior of the groundwater system in Karaj plain. For this purpose, the GMS model 318 was first calibrated under steady and unsteady conditions to determine the status of variation in 319 hydrodynamic coefficients of the aquifer. Then, to ensure the accuracy of the prepared aquifer 
320 simulation model, the model was validated based on new data which have not been used in the

321 calibration process.

322 By implementing the proposed coupled simulation-optimization model, the optimal trade-off 323 curve between the objective functions is extracted. Each trade-off curve contains numerous 324 optimal scenarios for operation of wells. Therefore, in this study, the MCDM methods were used 325 to extract the most appropriate exploitation of aquifer scenario in terms of objectives.

326 In this study, the MCDM methods used to determine the superior scenario are: weighted aggregate 327 sum product assessment (WASPAS), complex proportional assessment (COPRAS), technique for 328 order preference by similarity to ideal solution (TOPSIS), compromising programming (CP), and 329 modified TOPSIS (M-TOPSIS). Due to the different ranking of scenarios (points located on 330 optimal trade-off curves) in each of the MCDM methods, the BAM method was used to aggregate 331 the results of these five MCDM methods of ranking the solutions that generated by the NSGA-II 332 algorithm and determine the final ranking of each scenarios. Details of the decision-making 333 methods used can be found in the Banihabib et al. (2017) paper.

334 Based on the best scenario, the quantitative and qualitative behavior of aquifer is analyzed under 335 optimal operation. In fact, according to the optimal values obtained from this scenario, deciding 336 on existing operating conditions becomes easier and operating and decision-making managers can 337 appropriately present short-term and long-term plans for sustainable operation of the groundwater 338 system. 


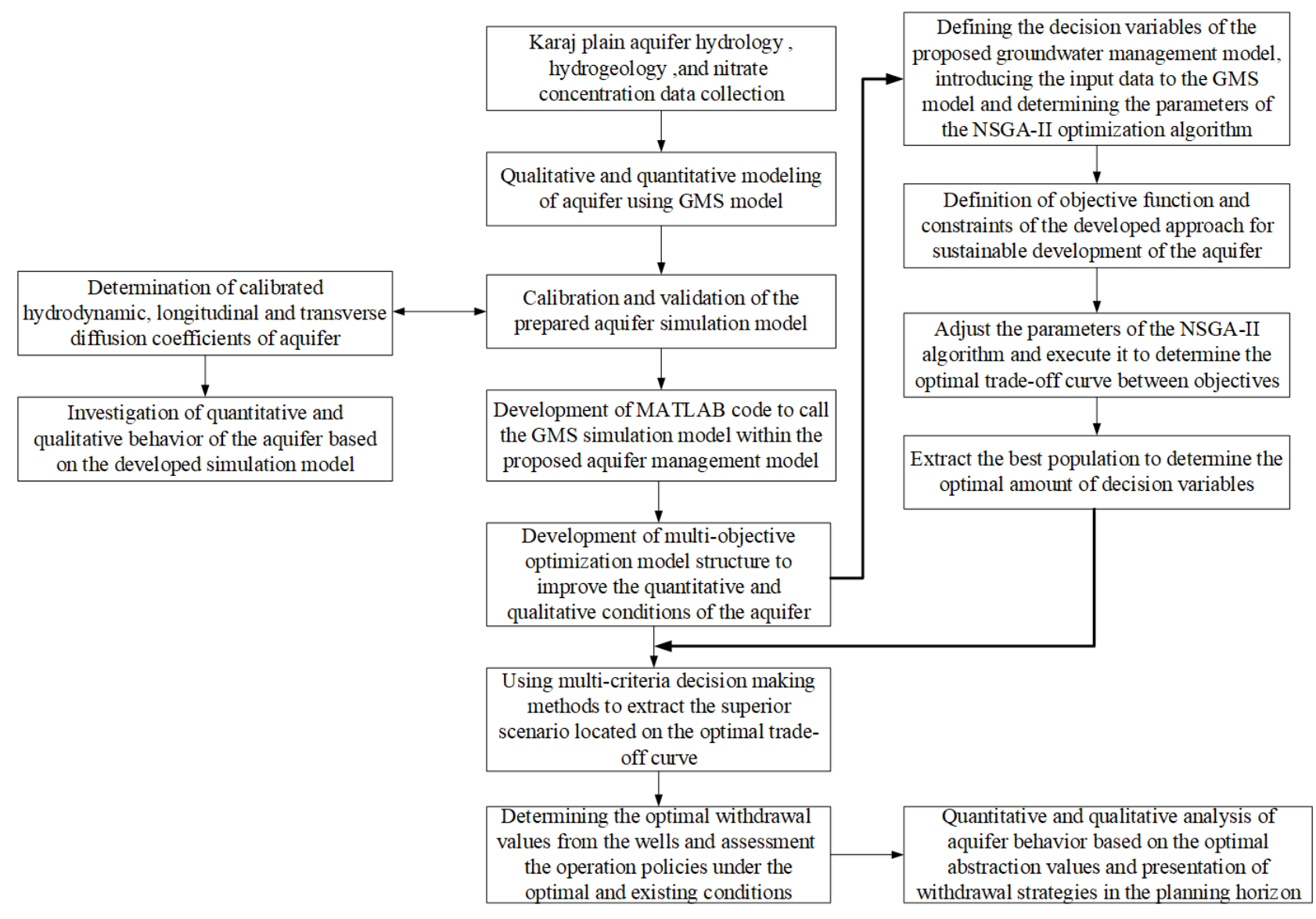

Fig. 2 The structure of the proposed multi-objective simulation-optimization model for

sustainable operation of the aquifer

\subsection{Aquifer simulation using prepared MATLAB code}

344 In this study, due to the high application of the GMS model and its very appropriate accuracy in

345 investigating the quantitative and qualitative behavior of the aquifer, code was prepared in

346 MATLAB environment with the aim of establishing link between this software and multi-objective

347 optimization algorithms. It should be noted that there are other methods such as using mfLab and

348 directly coupling the compiled MODFLOW Fortran code instead of calling GMS in the developed

349 multi-objective optimization management model that can be used for distributed modeling of the

350 aquifer. In this study, due to the simplicity of using GMS model, its widespread use by researchers, 
easy communication with MATLAB coding environment and proper execution speed, an approach

352 based on simultaneous calling of the GMS model in the multi-objective optimization model has

353 been used. The application of this method on a hypothetical aquifer has been investigated by

354 Majumder and Eldho (2015).

355 GMS is an application software for creating and simulating groundwater models from Aquaveo.

356 It features 2D and 3D geostatistics, stratigraphic modeling and a unique conceptual model

357 approach. Currently supported models include MODFLOW, MODPATH, MT3DMS, RT3D, 358 FEMWATER, SEEP2D, and UTEXAS.

359 The steps of aquifer simulation using the proposed MATLAB code are presented in the Fig. 3

360 flowchart. According to this figure, before establishing a link between the simulation model and

361 optimization, it is necessary to be prepared a conceptual model of the studied aquifer (Karaj plain)

362 based on data related to aquifer geometry and hydrogeological data such as bedrock, aquifer

363 topography, discharge and recharge components, storage coefficients, and hydraulic conductivity

364 of the aquifer, etc.

365 


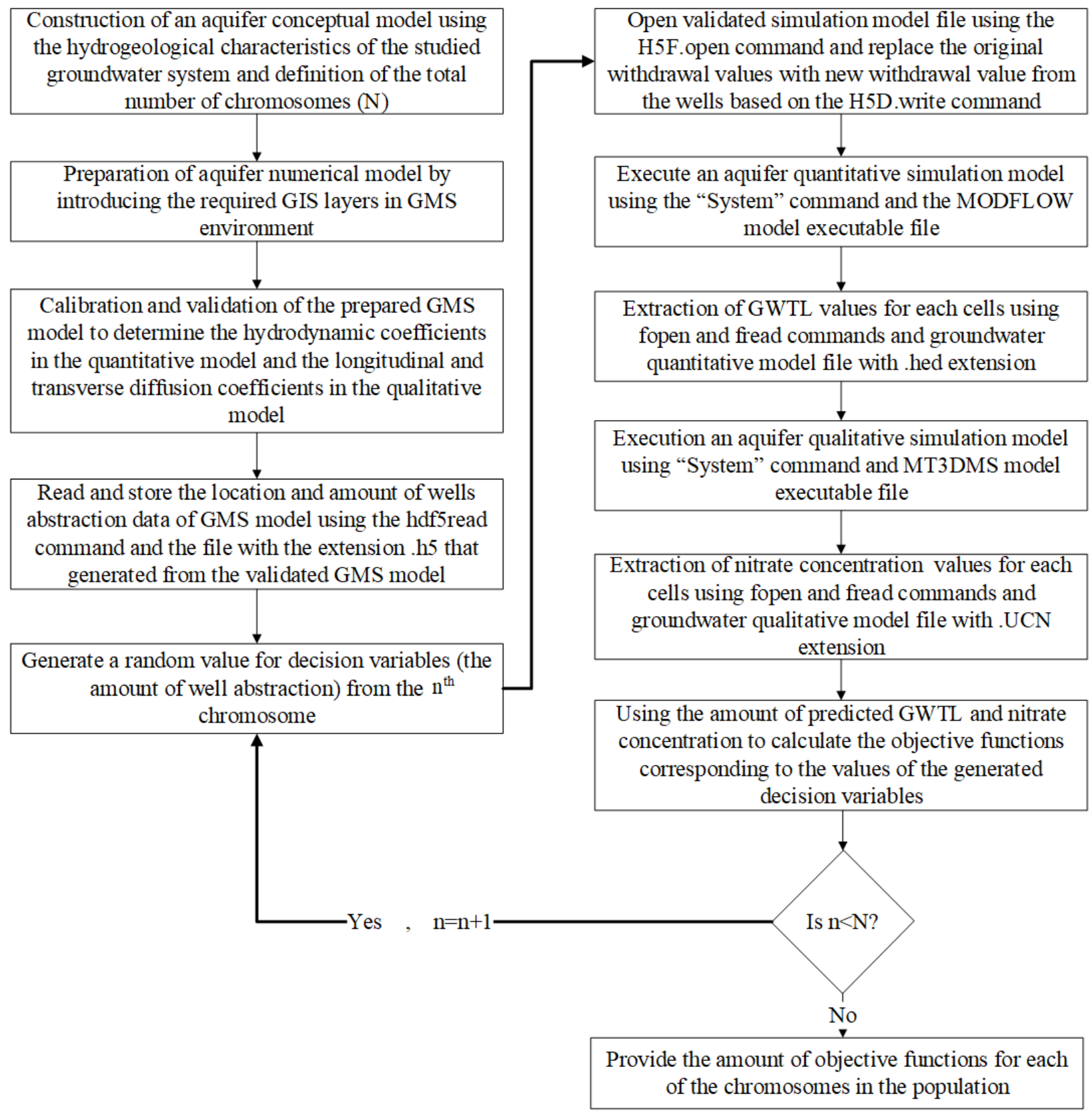

Fig. 3 The proposed MATLAB code structure to establish a link between GMS simulation model 

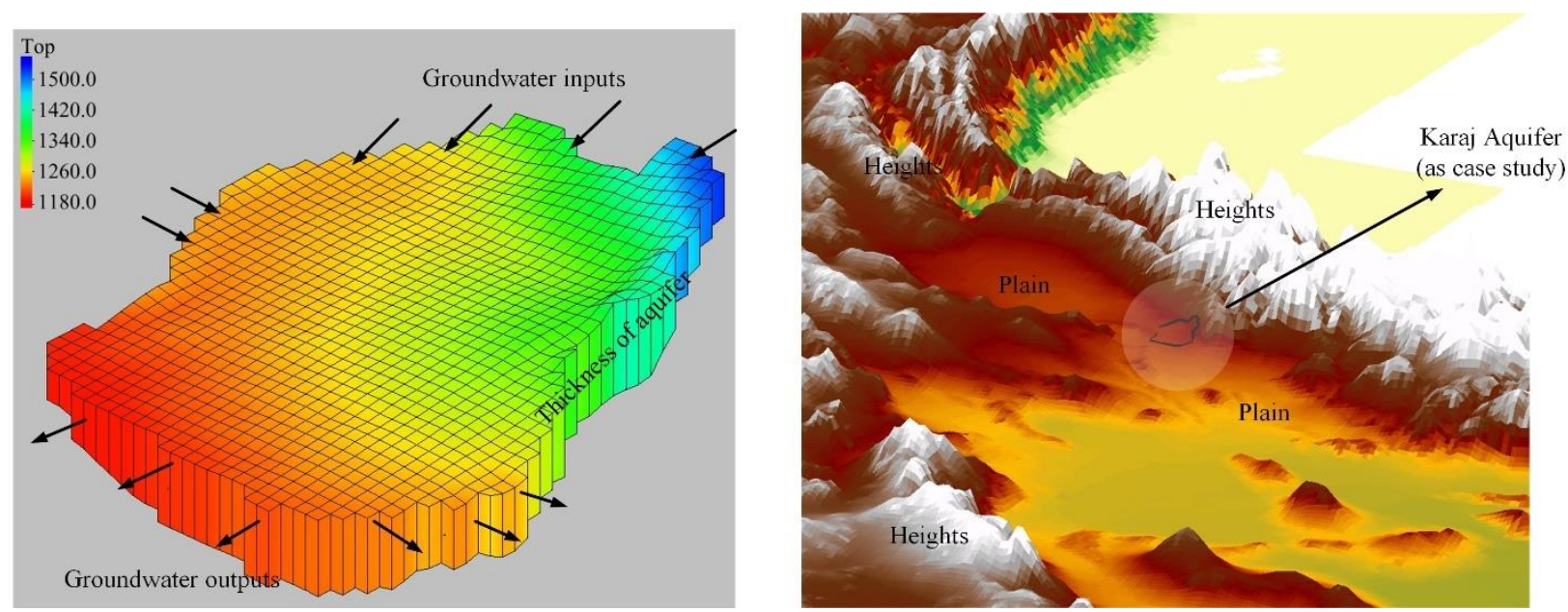

Fig. 4 Three-dimensional map of the aquifer area along with the conceptual model of the Karaj

After collecting the required information and preparing a conceptual model, it is necessary to design a groundwater flow model for implementation. In this stage, the modeling boundary, number of stress periods and time steps, type of aquifer boundary conditions, cellular amounts of recharge and discharge, and other aquifer hydraulic parameters are determined. In order to groundwater system simulation with the finite difference method, it is necessary to divide the aquifer area into a smaller number of zones which is called a cell. According to the geological condition, topography, area of case study, and the amount of available data from the Karaj plain, the grid with cells $500 \times 500$ meters and 44 rows and 39 columns, and containing 1017 active cells in the UTM geographical coordinate system was prepared.

384 The Karaj aquifer is unconfined and spreads throughout the plain. A single layer model has been 385 considered to simulate this aquifer, according to the condition and type of aquifer. The boundaries 386 of the modeling area are determined mainly by the spatial distribution of the observation wells 387 (piezometric wells). The northern borders of the study area adjacent to the southern heights of 388 Alborz and its eastern border cover the Karaj river. In order to determine the direction of 
groundwater movement and also to study the possible inflow and outflow fronts of groundwater,

390 boundary conditions were determined using the hydrogeological feature and prepared the GWTL

391 map in ArcGIS10.2 software. In terms of boundary conditions, considering that the trend of

392 groundwater movement from north and northwest to south and southeast and in the direction of

393 Karaj River, so the north and northwest borders were considered as the inflow to the groundwater

394 and the southeast and south borders as the groundwater outflow (Fig. 4). After determining the

395 boundaries of groundwater inflow and outflow of Karaj aquifer based on the observation wells

396 data, these boundaries were introduced to GMS tools as General Head Boundary (GHB) due to the

397 uncertainty of the volume of inflow and outflow from the boundaries of aquifer. In fact, using this

398 package and determining the amount of hydraulic conductivity of the inlet and outlet boundaries

399 and the level of groundwater at each time step, the amount of inflow and outflow from the aquifer

400 is calculated.

401 Other parameters that have been introduced to the GMS tools for simulation of Karaj aquifer are:

402 aquifer surface topographic, bedrock, initial hydraulic conductivity, monthly GWTL, location and

403 value of well discharge, initial nitrate concentration, recharge amounts by surface water resources,

404 agricultural return flow, domestic absorption wells and precipitation, and etc. As an example, the

405 topographic cell map, bedrock, initial GWTL, the location of the operation wells and the position

406 of the piezometers are presented in Fig. 5.

407 By performing calibration process under steady and unsteady conditions, the hydrodynamic 408 coefficients of the aquifer and the longitudinal and transverse diffusion coefficients are calibrated 409 and used for validation. In order to use the validated model during the optimization process, it is 410 first necessary to call and store data related to the location and amount of withdrawal from wells 
411 based on the validated simulation model. For this purpose, it is necessary to use the following code

412 in MATLAB environment:

413 Dwells=hdf5read('VerificationKarajAquifer.h5','/Well/07. Property');

414 In this code, "VerificationKarajAquifer" is the name of the validated groundwater simulation 415 model.

416 The amount of decision variables undergoes many variations during the optimization process to 417 achieve the optimal value, which is the satisfaction of the objective functions. Therefore, based on 418 these variations, it is necessary to calculate the value of objective functions in proportion to them. 419 For this purpose, it is necessary for each variation in the decision variables, the original value 420 (Dwells) replaced with new withdrawals values from wells and run a validated groundwater 421 simulation model. The following command is used to open the validated GMS model in MATLAB 422 environment and replacement of the new withdrawal values from wells:

423 plist = 'H5P_DEFAULT';

424 fid = H5F.open(VerificationKarajAquifer.h5','H5F_ACC_RDWR', plist);

425 dset_id = H5D.open(fid,'/Well/07. Property');

426 H5D.write(dset_id,'H5ML_DEFAULT','H5S_ALL','H5S_ALL','H5P_DEFAULT', Dwellsnew);

427 H5D.close(dset_id);

428 H5F.close(fid)

429 With the implementation of quantitative and qualitative simulation model using the following 430 command, the required parameters to calculate the value of the three defined objective functions, 431 namely monthly GWTL and nitrate concentration are extracted for each active cell:

432 - Command to call the executable file of the aquifer quantitative simulation model:

433 command = 'D:IKarajModel_MODFLOW'; 
$434 \quad[$ status, cmdout $]=\operatorname{system}($ command $) ;$

435 system('mf2k_h5_parallel.exe VerificationKarajAquifer.mfn');

436 - Code to extract the amount of simulated GWTL:

437 fid2=fopen(VerificationKarajAquifer.hed','r');

438 GWTL=fread(fid2,'float32=>float32');

439 - Command to call the executable file of the aquifer qualitative simulation model:

440 command = 'D:\KarajModel_MT3DMS';

$441 \quad[$ status,cmdout $]=$ system $($ command $) ;$

442 system('mt3dms53.exe erificationKarajAquifer.mts');

443 - Code to extract the amount of simulated nitrate concentraction:

444 fid=fopen('D:\KarajModel_MT3DMS $\backslash M T 3 D 001 . U C N ', ' r ')$;

445 No3_concentration=fread(fid,'float32=>float32');

447 The process described above is repeated for each variation in the decision variables located on the 448 chromosomes of the NSGA-II algorithm. With the completion of calculating the value of the 449 objective functions for all chromosomes (a population), the selection, crossover and mutation and 450 non-domination-sort operators are applied to the chromosomes in order to generate an improved 451 population to achieve the optimal trade-off curve between the objective functions. 


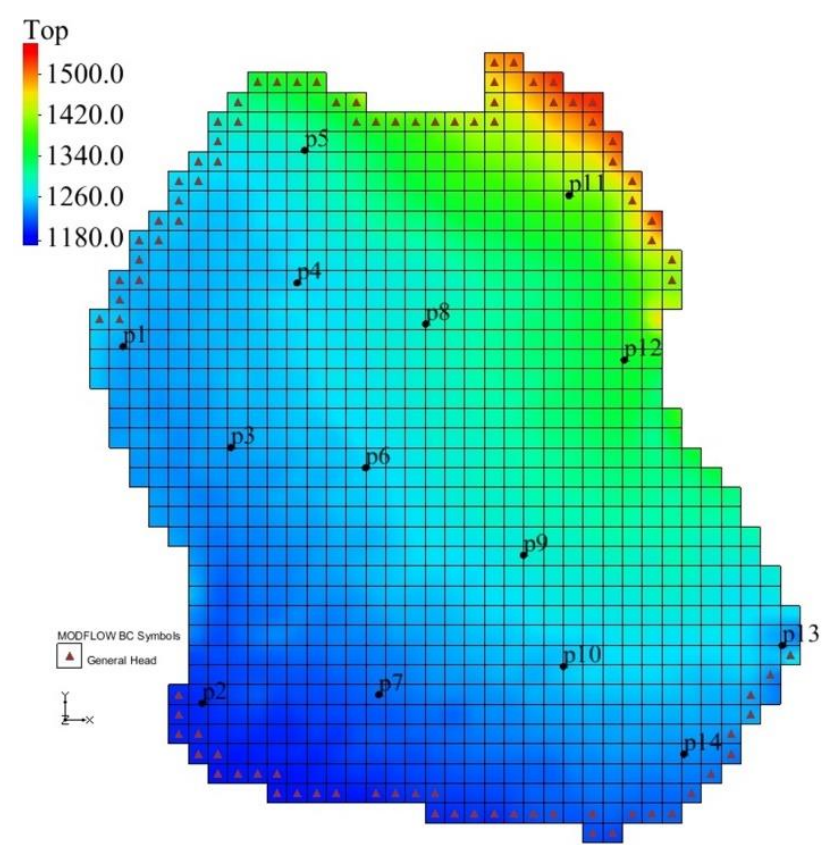

(a)

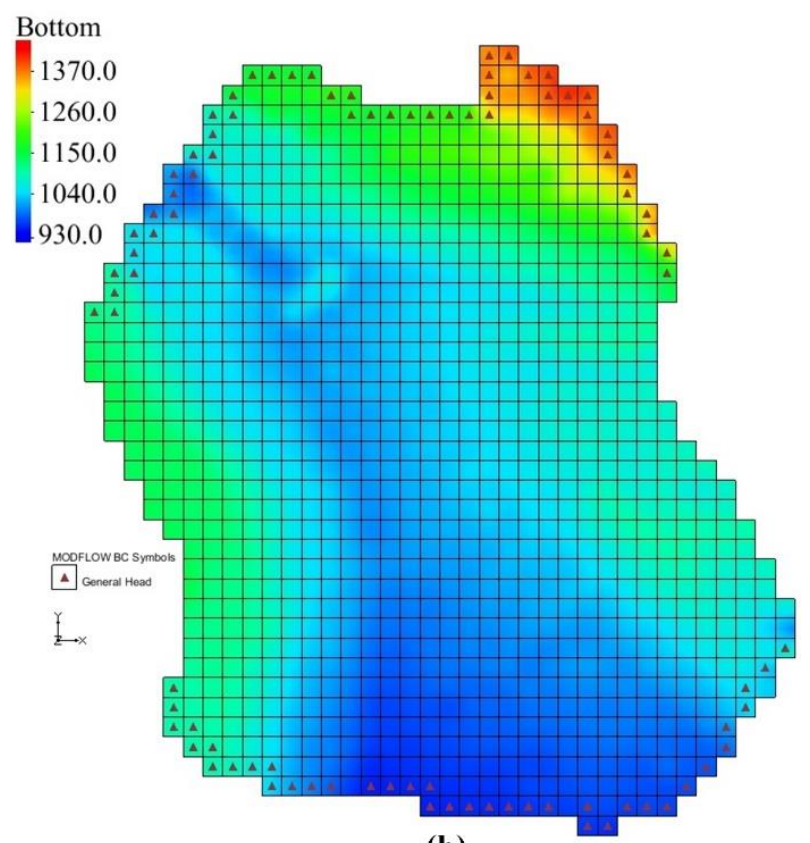

(b)

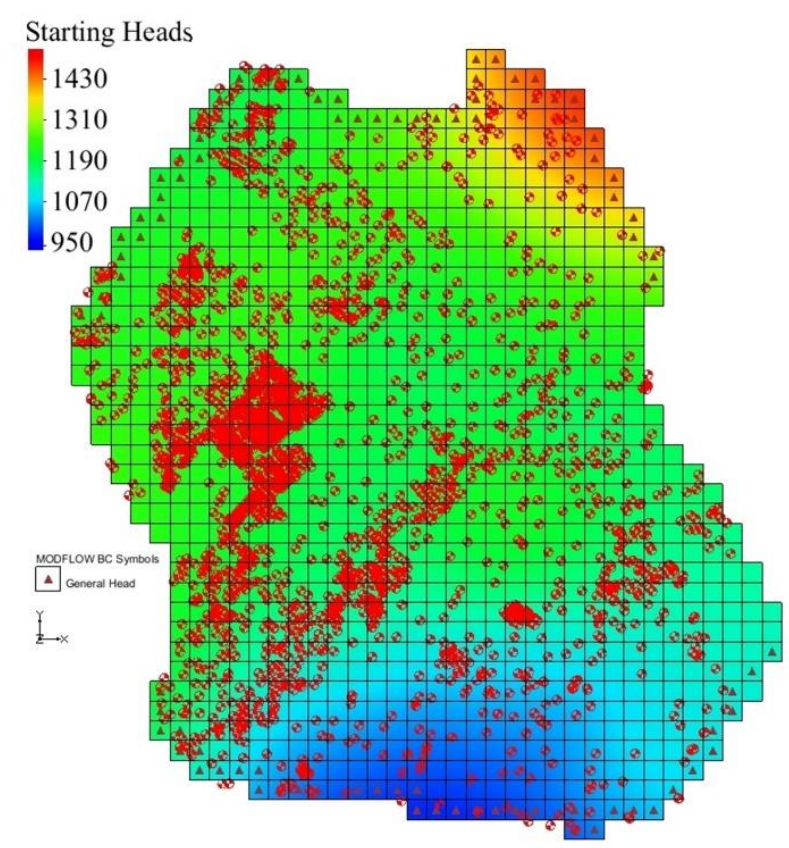

(c)

$454 \quad$ Fig. 5 Spatial distribution of aquifer modeling parameters, a) Aquifer topography (m) and 455 position of piezometers, b) Aquifer bedrock (m), c) Initial GWTL (m) and location of operation wells 
459 For sustainable management of groundwater resources using the proposed model, it is necessary to calibrate the aquifer simulation model. Then, by implementing the multi-objective optimization

461 model and extracting the operation scenarios of groundwater system, the optimal operation policies

462 of wells can be determined. In this section, initially, the results of the aquifer quantitative and 463 qualitative simulation model and then the analysis and discussion of the optimization management 464 model results are presented.

\section{$465 \quad 4.1$ Results of aquifer simulation model}

466 By implementing a prepared quantitative simulation model under steady condition and based on 467 the GWTL of observation wells for September 2010, first by manual method (trial and error), the 468 initial hydraulic conductivity was somewhat calibrated. Then, according to the appropriate 469 capabilities of GMS software in calibration of numerical models, for calibration of hydraulic 470 conductivity $(\mathrm{K})$ values, a number of pilot points are defined in the model and based on the values 471 obtained from manual calibration, an initial value of $\mathrm{K}$ was assigned to each of these points.

472 In the next step, the software calculates the hydraulic conductivity values for all model cells by 473 interpolating the initial values given for the pilot points and simulates the GWTL distribution in 474 the study area by implementing the model using these values.

475 Finally, by comparing the observational and computational GWTL values at the observation wells, 476 the computational error of the model is determined and the model tries to provide a better 477 description of the distribution of this parameter in the study area by modifying the hydraulic 478 conductivity values at the pilot points.

479 The interpolation method used for the hydraulic conductivity of pilot points is the kriging method, 480 which has more capabilities than other existing interpolation methods (such as IDW) and provides 
481 better control over the output results of the interpolation process. The calibrated values of the 482 hydraulic conductivity for the modeling region are shown in Fig. 6. Also, the scatter plot and the 483 bar chart diagram between the observed and simulated GWTL in piezometric wells in order to 484 assessment the accuracy of the calibrated model results are drawn in Fig. 7. As shown in this figure, 485 overall, relatively good agreement between the observed and simulated GWTL are found in all 486 piezometers.

487 For simulation in unsteady condition, it is necessary to construct an unsteady model for the study 488 area so that the temporal variation of the aquifer is assessed in this study. The time period 489 considered in this model is one water year (2010-2011). In this model, the number of stress periods 490 are 12. All hydrological parameters for different stress periods are assigned to cells of aquifer 491 according to the data available in different months. By implementing a quantitative simulation 492 model under unsteady conditions, the spatial distribution of the calibrated specific yield coefficient 493 can be presented in Fig. 8. To evaluate the accuracy of the unsteady calibration results, the GWTL 494 hydrograph in the studied piezometers are presented in Fig. 9. According to this figure can be 495 found that the aquifer parameters have been well calibrated in order to modeling the real conditions 496 governing the groundwater system of the Karaj plain.

497 In order to evaluate the prediction accuracy of the calibrated GMS model, the following statistical 498 performance indices were used:

$499 \quad M S E=\frac{\sum_{i=1}^{n}\left(x_{m i}-x_{c i}\right)^{2}}{N}$

$500 \quad M A E=\frac{\sum_{i=1}^{n}\left|x_{m i}-x_{c i}\right|}{N}$

$501 \quad N R M S E=\frac{R M S E}{\overline{x_{m l}}}$

502 where, $x_{m i}$ and $x_{c i}$ are the measured and simulated values, respectively. Also, $\overline{x_{m l}}$ is the average 503 of measured values. The Normalized Root Mean Square Error (NRMSE) the RMSE facilitates the 
504 comparison between models with different scales. The NRMSE which relates the RMSE to the 505 observed range of the variable. Thus, the NRMSE can be interpreted as a fraction of the overall 506 range that is typically resolved by the model. In all the above error indicators, the values closer to 507 zero show that the model performance is more appropriate.

508 By calculating the above error indices for all aquifer piezometers, it can be seen that the calibrated 509 model can simulate the quantitative behavior of the aquifer to assess the groundwater level with 510 appropriate accuracy (Table 1).

511 Qualitative model of Karaj plain aquifer done for modeling monthly variations of nitrate 512 concentration. For this purpose, MT3DMS model was used to aquifer qualitative simulation. 513 Accordingly, the qualitative conceptual model of the aquifer was implemented on a quantitative 514 unsteady model. According to the available data and in order to adapt to the prepared quantitative 515 model, the qualitative data measured in the observation wells of the period 2010-2011 have been 516 used to calibration of model. Using the manual method and changing the longitudinal dispersion 517 parameter and the amount of nitrate entering the aquifer, the qualitative model was calibrated. Fig. 51810 shows the calibrated value of the aquifer longitudinal dispersion coefficient. According to this 519 figure, the value of longitudinal dispersion coefficient in the aquifer varies from 0.05 in the central 520 and western parts to 0.26 in the southeastern parts of the aquifer. 


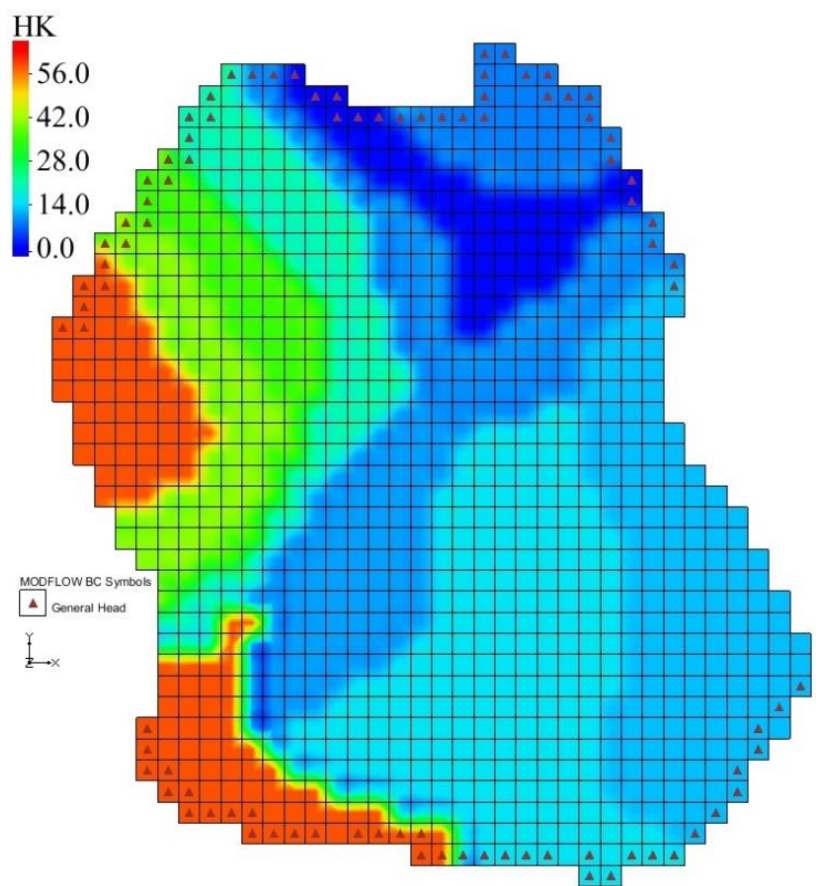

Fig. 6 The map of calibrated hydraulic conductivity $(\mathrm{m} /$ day)

523 


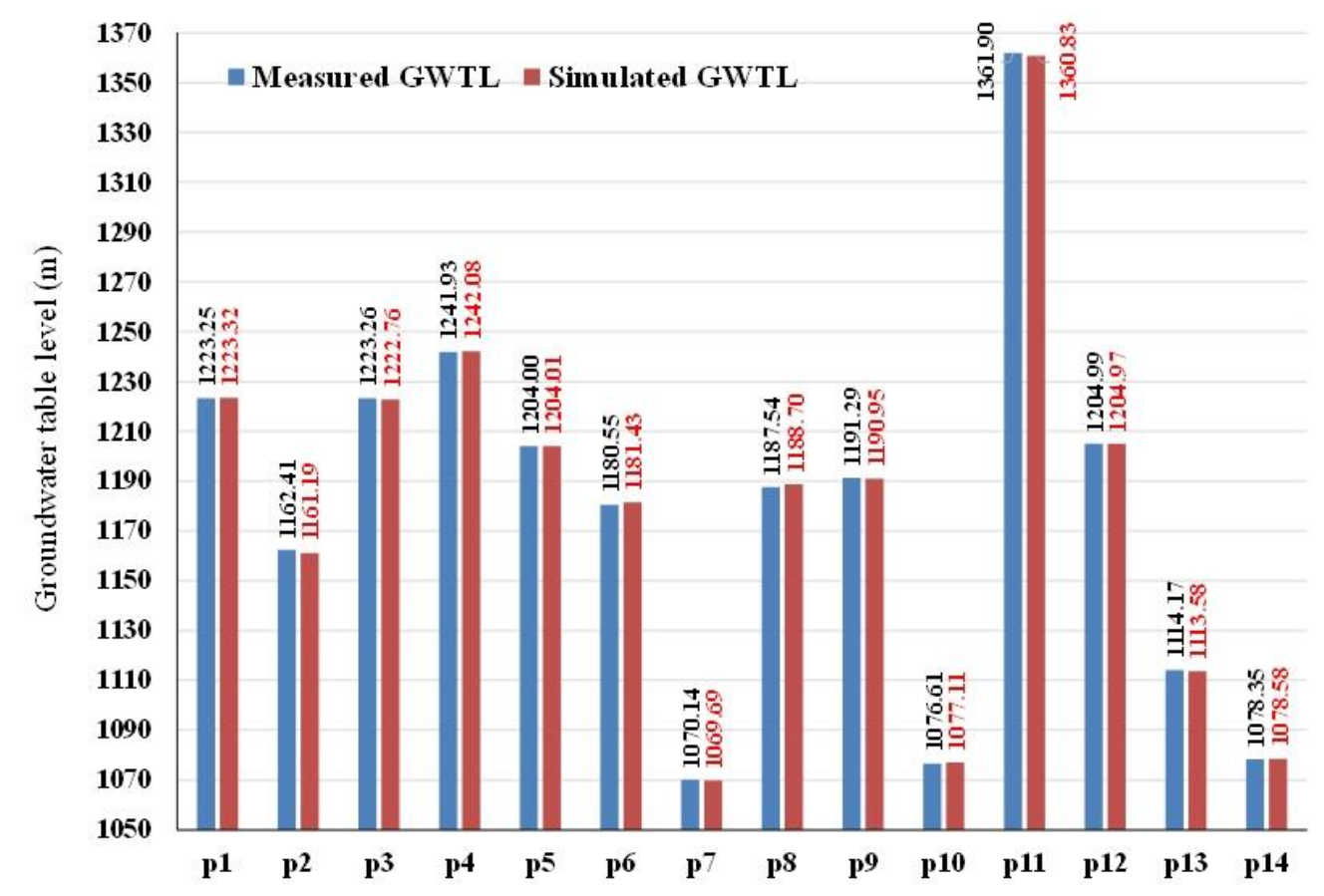

(a)

Name of piezometer

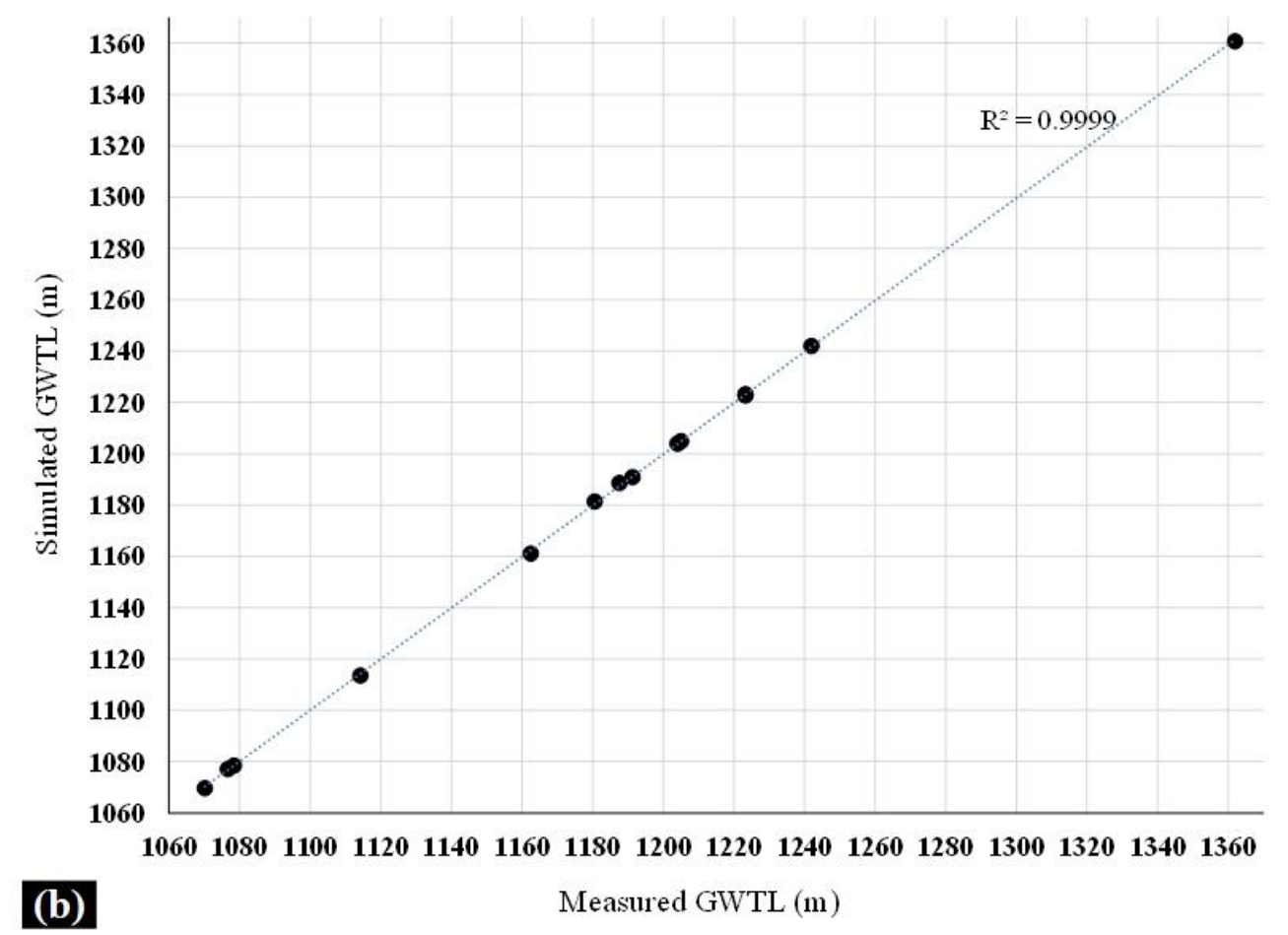

Fig. 7 The bar chart diagram (a) and scatter plot (b) between the observed and simulated GWTL in piezometric wells under steady condition 


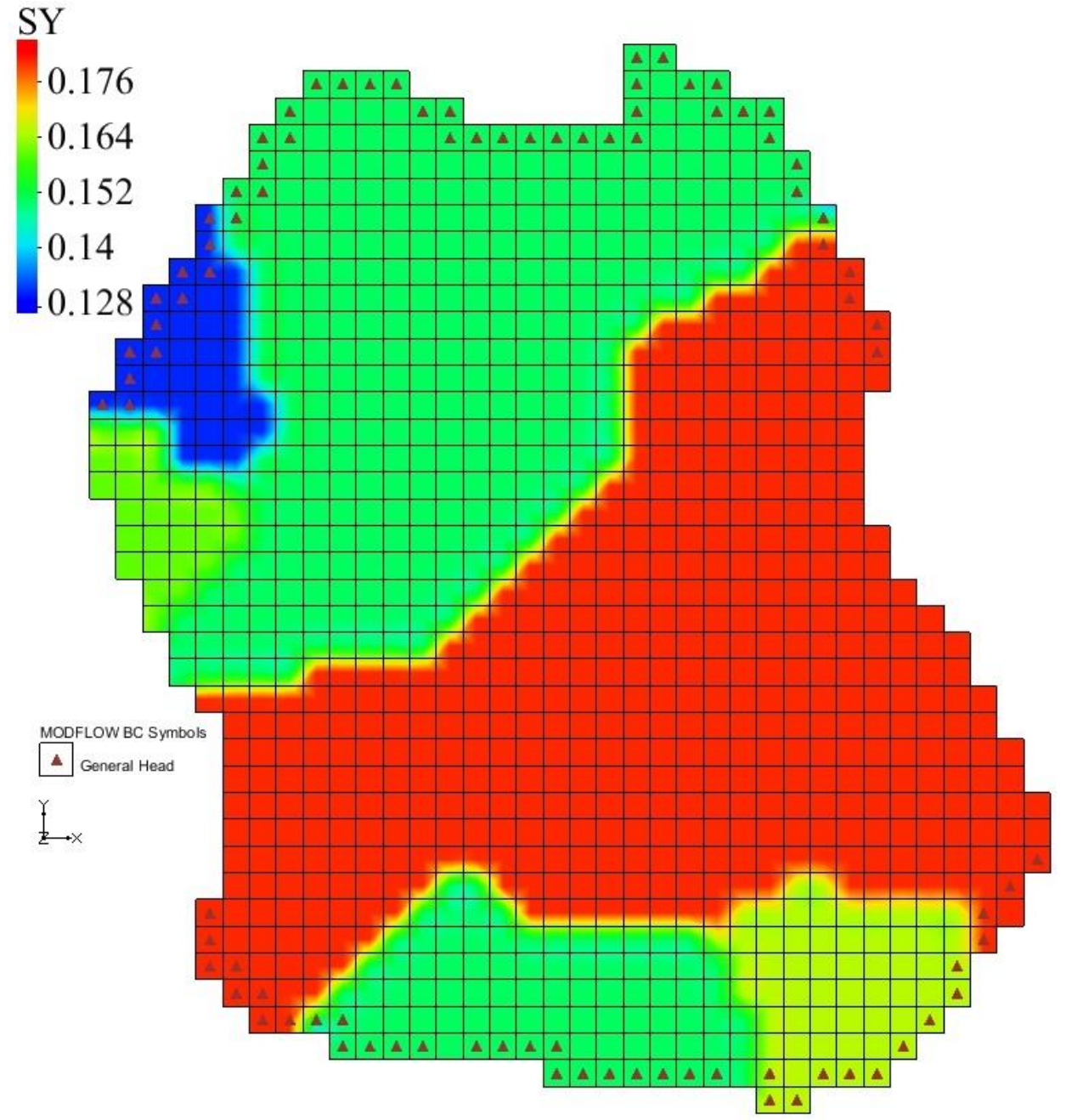

Fig. 8 The map of calibrated specific yield coefficient (dimensionless) 

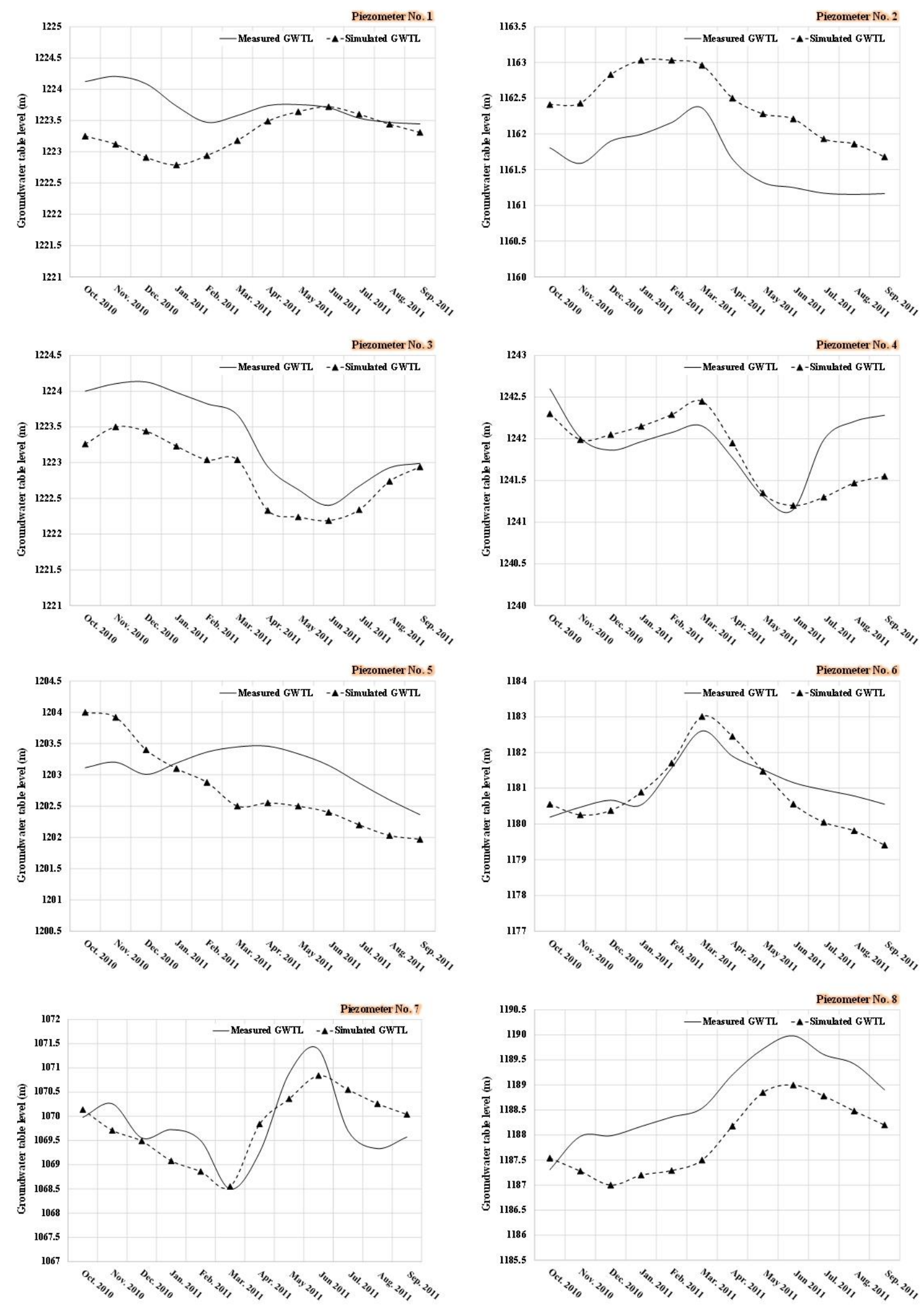

532 Fig. 9 Comparison of observed and simulated GWTL hydrographs at the location of piezometers 

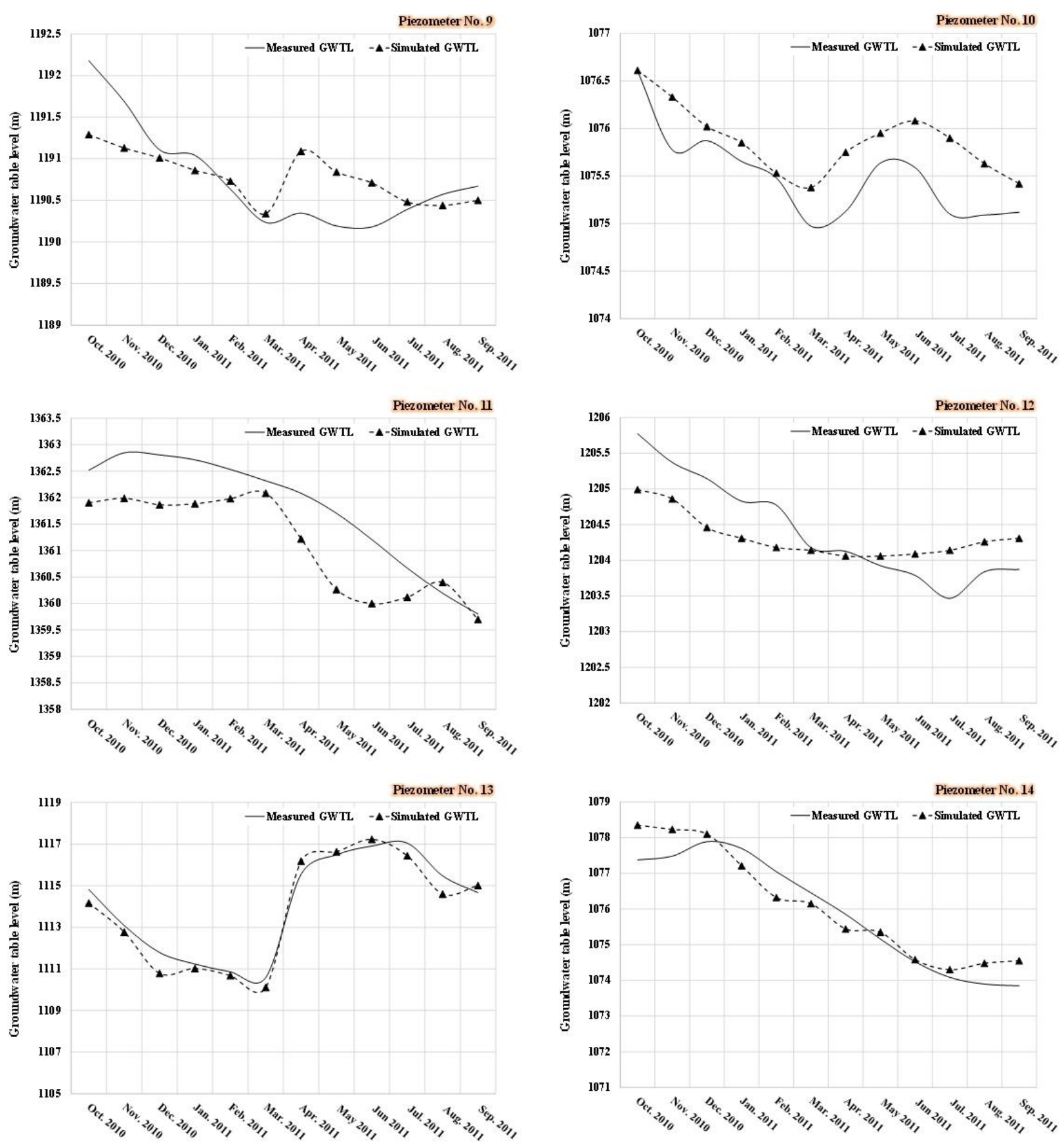

Fig.9 (continue) 
Table 1. Performance evaluations of piezometers during the calibration of GMS model

\begin{tabular}{|c|c|c|c|}
\hline Piezometer Name & MSE & MAE & NRMSE \\
\hline p1 & 0.395 & 0.4672 & 0.0005 \\
\hline p2 & 0.670 & 0.8027 & 0.0007 \\
\hline p3 & 0.306 & 0.4979 & 0.0005 \\
\hline p4 & 0.157 & 0.3026 & 0.0003 \\
\hline p5 & 0.467 & 0.6368 & 0.0006 \\
\hline p6 & 0.359 & 0.4978 & 0.0005 \\
\hline p7 & 0.322 & 0.5004 & 0.0005 \\
\hline p8 & 0.793 & 0.8618 & 0.0007 \\
\hline p9 & 0.206 & 0.3534 & 0.0004 \\
\hline p10 & 0.190 & 0.3688 & 0.0004 \\
\hline p11 & 0.641 & 0.7006 & 0.0006 \\
\hline p12 & 0.242 & 0.4301 & 0.0004 \\
\hline p13 & 0.298 & 0.4782 & 0.0005 \\
\hline p14 & 0.291 & 0.4674 & 0.0005 \\
\hline
\end{tabular}

540

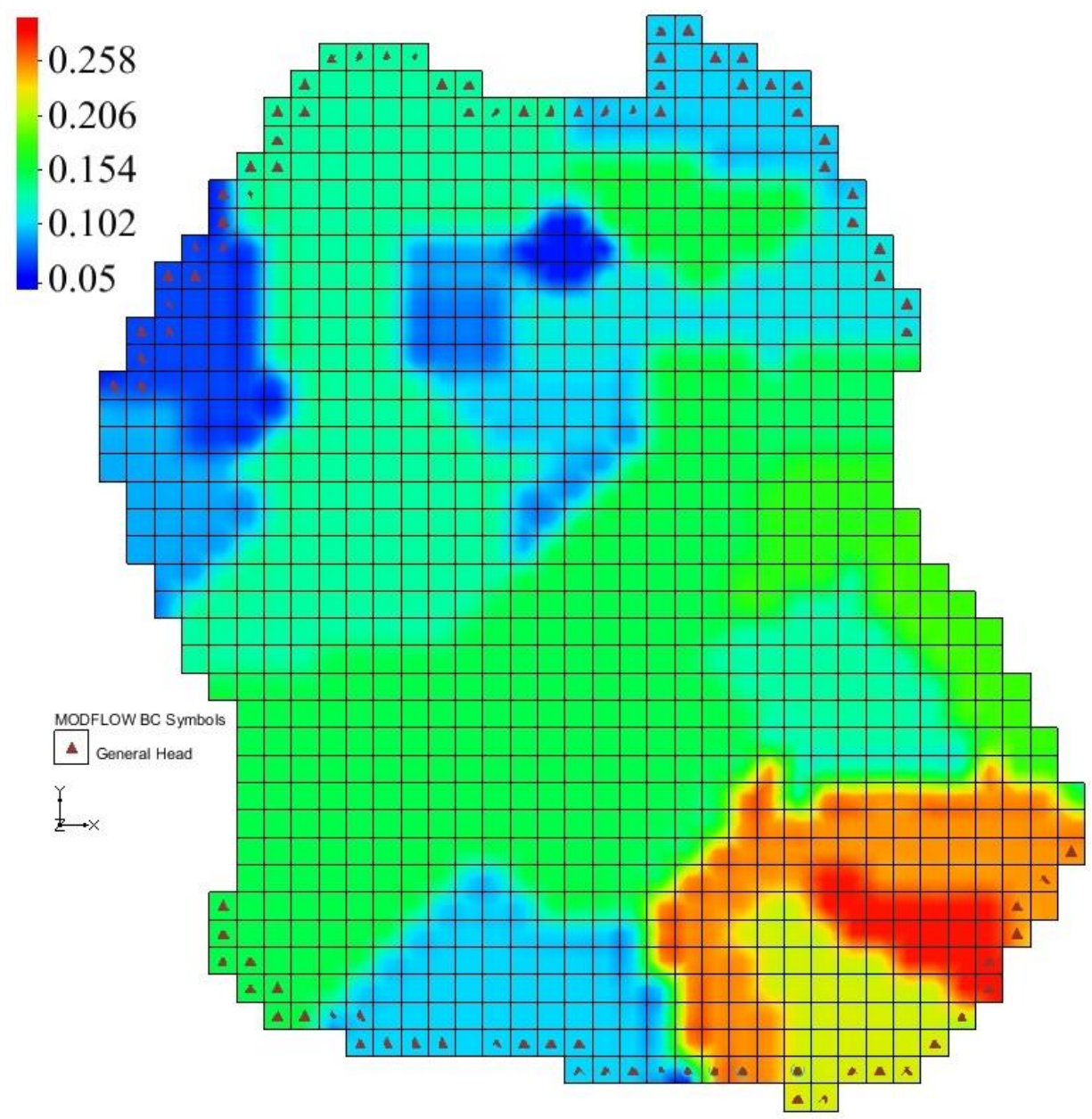




\subsection{Results of developed optimization management model}

545 In this study, an NSAGA-II multi-objective algorithm, developed in the MATLAB-R2018b

546 environment, has been used to achieve the optimal trade-off curve between objectives. Parameters

547 related to crossover and mutation operators were determined using trial and error method. Also,

548 the tournament operator was used to select the parent's chromosomes. Since the initial population

549 plays a vital role in time consuming of optimization process and distributing the solutions on trade-

550 off curve, so in this study, the initial population with feasible solutions was identified. In the

551 NSGA-II algorithm, the population size was considered to be 150. By implementing the developed

552 three-objective simulation-optimization model on a computer with 16 gigabyte RAM and CPU 553 core i7-9700, the optimal trade-off curve was determined.

554 Regarding the computational costs of implementing the proposed model, it can be stated that based 555 on the properties of the mentioned computer, 64.58 hours are required to perform 500 iterations of 556 the proposed model. It should be noted that the execution time of each aquifer simulation model 557 based on MATLAB code is 3.1 seconds.

558 According to optimal trade-off curve, the minimum and maximum value of first objective function 559 (sum of drawdown of GWTL in drinking wells) were $3554.8 \mathrm{~m}$ and $3742.5 \mathrm{~m}$ (equivalent to an 560 average drawdown of $1.45 \mathrm{~m}$ and $1.53 \mathrm{~m}$ per well) in total planning horizon (three years), 561 respectively. The minimum and maximum value of second objective function (sum of nitrate 562 concentration in cells containing operation wells) were $3347638.5 \mathrm{mg} / \mathrm{l}$ and $3352001 \mathrm{mg} / \mathrm{l}$ (on 563 average, 56.87 and $56.94 \mathrm{mg} / \mathrm{l}$ nitrate concentration per well and monthly), respectively. Also, 564 the range of third objective function (sum of withdrawal rate from wells) are estimated between 
226.11 MCM and 230.92 MCM, respectively. These minimum and maximum values of objective function are used to determine the priority of each of the solutions on optimal trade-off curve using MCDM methods.

\subsubsection{Extraction of the superior solution based on MCDM methods}

in this study, in order to determine the rank of each solution located on the optimal trade-off curve, seven MCDM methods called WASPAS, COPRAS, TOPSIS, $C P_{p=\infty}, C P_{p=2}$ and $C P_{p=1}$ have been used. By applying these decision-making methods to the optimal solutions, the rank of each solution based on each MCDM methods was determined as Table 2. According to this table, the ranking for the solutions is very different with miscellaneous MCDM methods, and it is not possible to provide the final rank. For this purpose, the BAM method was applied to select the final rank that has a higher Berda scoring.

Based on NSGA-II result can be found that 139 and 11 solution (of the 150 generated solution) are considered as non-dominate and dominate solutions. Therefore, ranking is done on 139 nondominate solutions and if a solution has a rank of one, its Berda scoring will be equal to 138 . Similarly, this Berda scoring can be easily calculated for other solutions. By performing this process for each MCDM method and extracting the sum of Berda scoring obtained for each solution, the final Berda scoring of solutions is determined. By sorting descending of scores, can be specified the final rank of each solution in the form of Fig. 11. 
Table 2. The rank of solutions on the optimal trade-off curve using MCDM methods

\begin{tabular}{|c|c|c|c|c|c|c|c|}
\hline Method & $C P_{p=1}$ & $C P_{p=2}$ & $C P_{p=\infty}$ & TOPSIS & $M-T O P S I S$ & COPRAS & WASPAS \\
\hline 1 & 120 & 118 & 74 & 117 & 20 & 4 & 23 \\
\hline 2 & 60 & 17 & 35 & 60 & 78 & 40 & 82 \\
\hline$\cdot$ & & $\cdot$ & $\cdot$ & 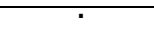 & $\cdot$ & e & $\cdot$ \\
\hline . & . & . & . & . & . & . & . \\
\hline 35 & 32 & 43 & 96 & 34 & 106 & 116 & 106 \\
\hline 36 & 117 & 98 & 14 & 124 & 15 & 45 & 20 \\
\hline . & & . & . & . & . & . & . \\
\hline . & . & . & . & . & . & . & . \\
\hline 75 & 124 & 130 & 88 & 119 & 24 & 51 & 18 \\
\hline 76 & 107 & 103 & 77 & 103 & 42 & 93 & 37 \\
\hline 77 & 84 & 42 & 1 & 89 & 44 & 47 & 53 \\
\hline 78 & 22 & 53 & 112 & 20 & 119 & 109 & 115 \\
\hline 79 & 101 & 83 & 38 & 102 & 37 & 20 & 38 \\
\hline . & & . & . & 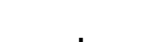 & . & . & . \\
\hline . & . & ${ }^{\circ}$ & . & . & r. & . & . \\
\hline 108 & 52 & 8 & 17 & 52 & 83 & 34 & 85 \\
\hline 109 & 34 & 78 & 106 & 37 & 108 & 79 & 108 \\
\hline 110 & 65 & 19 & 31 & 65 & 74 & 32 & 74 \\
\hline 111 & 106 & 92 & 41 & 109 & 28 & 21 & 32 \\
\hline . & & . & . & & . & . & . \\
\hline . & & . & . & 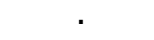 & . & . & . \\
\hline 138 & 69 & 27 & 56 & 69 & 71 & 80 & 70 \\
\hline 139 & 75 & 46 & 62 & 75 & 65 & 81 & 65 \\
\hline
\end{tabular}


Based on Fig. 11, it can be seen that solution 108 is in the first rank (selected scenario) in terms of satisfy three proposed objective functions simultaneously. Accordingly, the optimal decision

591 variables in proportion to this solution, which contains optimal values of withdrawing from

592 operation wells, are evaluated as a desirable alternative compared to another alternative located on 593 the optimal trade-off curve. Based on the results of alternative number 108, can be extracted 594 optimal amounts of groundwater abstraction from the aquifer for sustainable quantitative and 595 qualitative development. Also, based on these values, the quantitative and qualitative analyzes are 596 carried out on the status of each well to determine the effects of the proposed approach on 597 improving the quantitative and qualitative status of the aquifer.

598

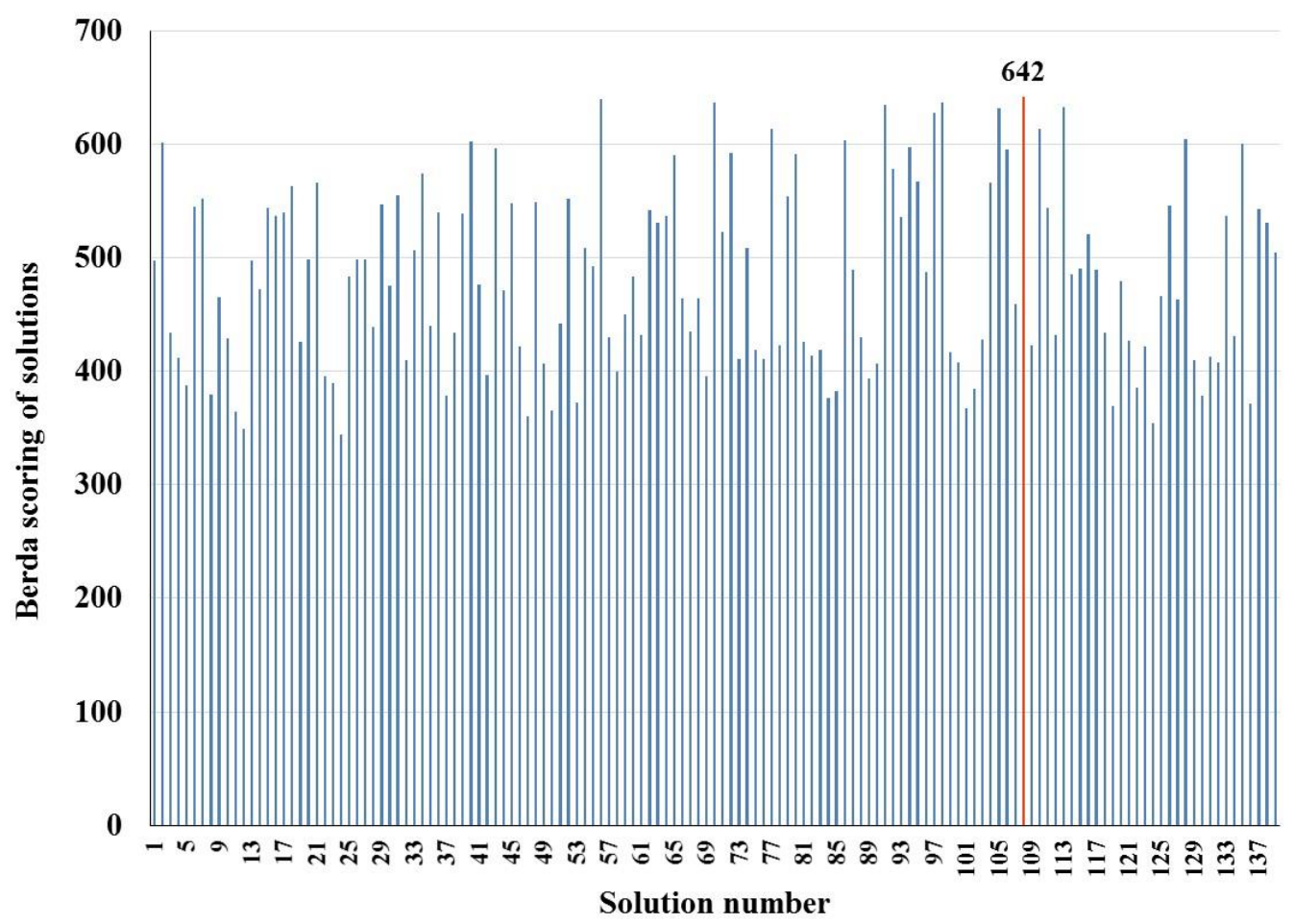


Based on the selected scenario and considering the optimal allocation of existing wells, it can be concluded that for establishing stability in the quantitative and qualitative status of the aquifer, it is necessary to reduce the current abstraction (471.55 MCM) to $228.49 \mathrm{MCM}$ (with a 51.55\%

607 reduction) over the planning horizon (Fig. 12). By applying the proposed approach, the 608 quantitative behavior of the aquifer has dramatically improved, so that the reduction of the 609 pumping of the wells has led to an increase of $4.6 \mathrm{~m}$ in GWTL (an average of $19 \mathrm{~cm}$ per month) 610 over three years (Fig. 13).

611 The response of the aquifer to the reduction of pumping is indicative of the high sensitivity of the 612 aquifer to the stresses on it. Therefore, in order to water supply demands of the study area, it is 613 necessary to be planned other available surface water resources such as increasing the allocation 614 of Karaj dam, increasing the amount of water transferred from Taleghan dam. Also, in order to 615 achieve aquifer sustainable development, water consumption must be decreased in different 616 sectors and water use efficiency increased in the agricultural section.

617 To observe the status of GWTL rise under optimal abstraction conditions, the GWTL hydrograph 618 in the operation wells has been drawn in different positions of aquifer according to Fig. 13.

619 The results show that in most parts of the aquifer, the GWTL is rising, and this is especially 620 significant in situations where the number of wells is high. This is due to increase in the saturation 621 thickness of the aquifer as a result of reduced withdrawal. It should be noted that this increase in 622 the GWTL will reduce the cost of pumping and decreases nitrate concentration as a result of 623 increased saturation thickness and dilution of the quality parameters (especially nitrate).

624 Histogram analysis of GWTL variation in 2453 operation wells shows that with the 625 implementation of optimal withdraw policies, $24.13 \%$ of wells (592 wells) experience an increase 
627 are equivalent to 339 and 343 wells, will benefit from an increase of 4-4.5 $\mathrm{m}$ and 5-5.5 $\mathrm{m}$ in their

628 GWTL, respectively. Other wells, similar to Fig. 14, will have a GWTL rise. It is worth mentioning

629 that after applying the optimal allocation results from wells, in 7 wells the GWTL increases to

630 more than $12 \mathrm{~m}$ in three years.

631 Since the Karaj aquifer area is $254.25 \mathrm{~km}^{2}$, an increase of $4.6 \mathrm{~m}$ in the GWTL, including a specific

632 yield of 0.163 , will lead to the annual addition of 95.3 MCM of water to the saturation thickness

633 of the aquifer. This amount, which is equivalent to $41.7 \%$ of the total optimal withdrawal from 634 wells, can lead to an increase in the static reservoir volume of the Karaj plain aquifer in the long635 term.

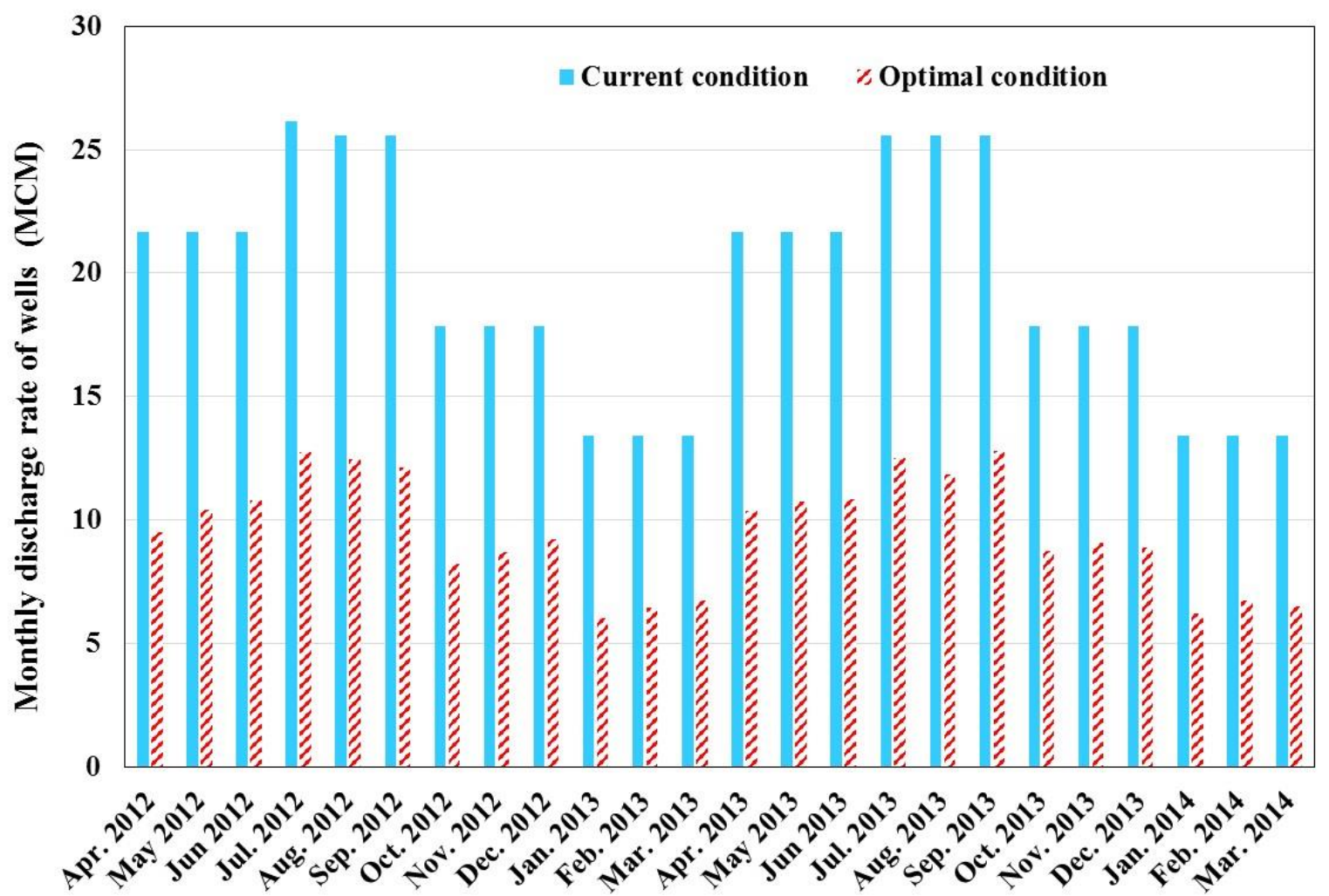

637 Fig. 12 Comparison of the monthly withdrawal from wells under optimal and current conditions 638 


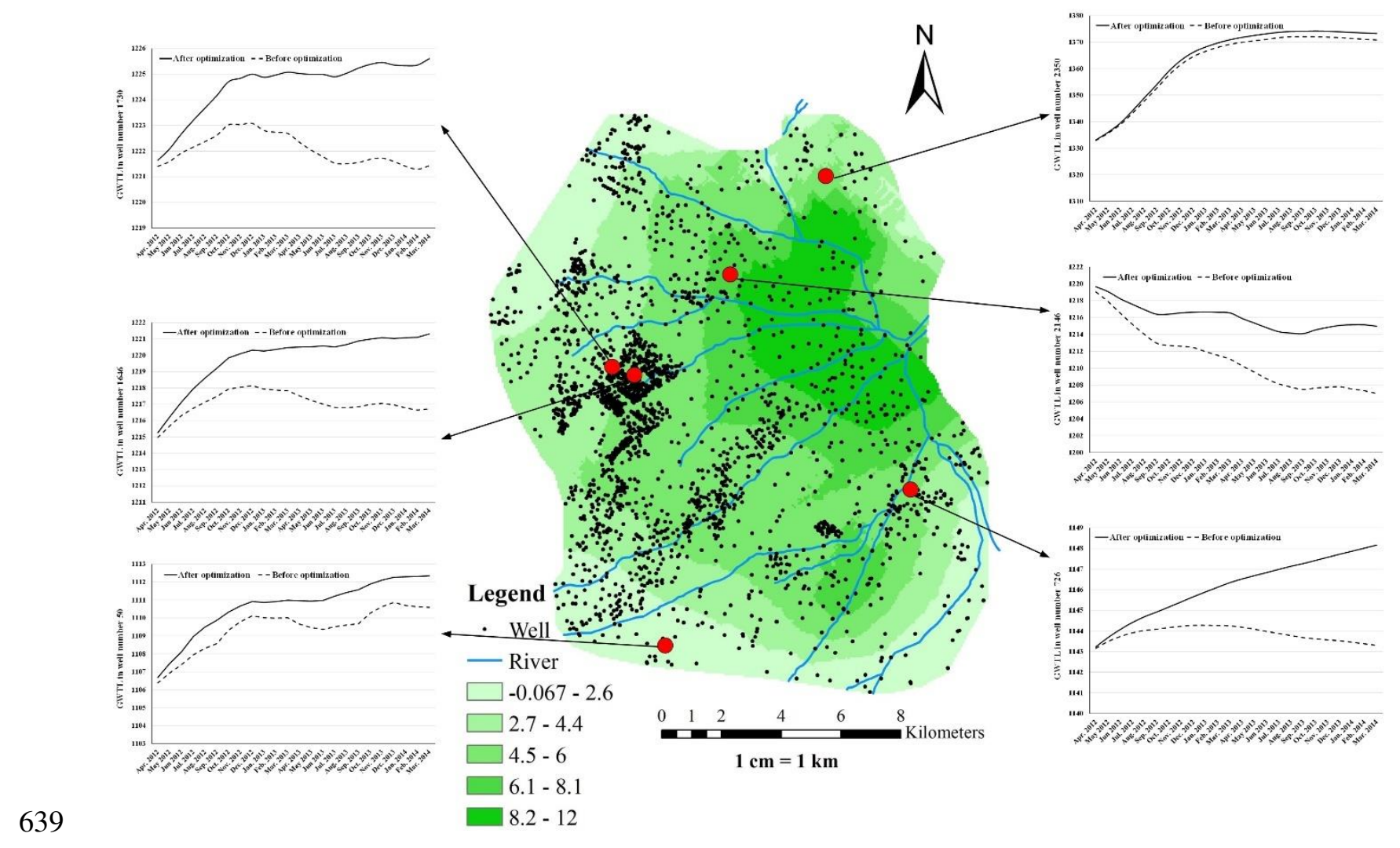

640

Fig 13. The rate of GWTL variation after the implementation of the proposed model

641

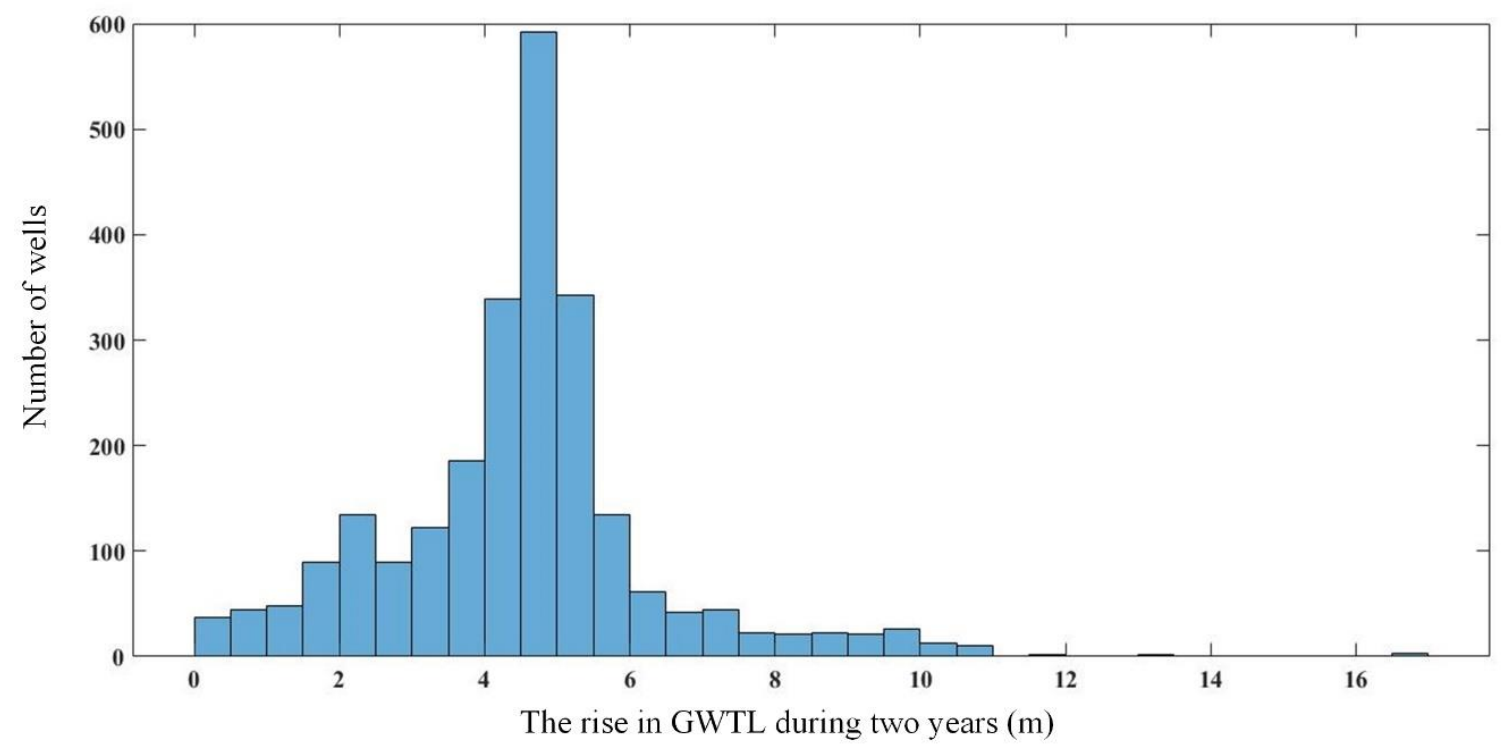

Fig. 14 GWTL variation histogram in 2453 studied operation wells as a result of applying optimal withdrawal policy 
$646 \quad$ 4.2.3 Investigation of the aquifer qualitative status under optimal abstraction conditions

647 To investigate the qualitative status of Karaj plain aquifer in terms of nitrate parameter, the results

648 of the extracted from the best scenarios, which derived from the optimal trade-off curve, are

649 analyzed. For this purpose, first, the general process governing the qualitative status of the aquifer

650 is described after applying the optimal pumping policies to the aquifer operation resources, and

651 then details related to the qualitative variations made on wells during the planning horizon are

652 presented.

653 A study on the time series of nitrate variations over the three years (2012-2014) shows that despite

654 a significant reduction in the pumping of wells, the average reduction in nitrate concentration was

655 about 3\% (Fig. 15). This is due to the severe pollution of the Karaj plain aquifer as a result of the

656 entry of urban and agricultural wastewater. If these optimal operating conditions persist, this

657 reduction in nitrate concentration can be intensified by utilizing the municipal wastewater

658 collection system over a period of 10 years and can be reduced to less than the permissible limit

659 of nitrate in drinking water (That is $50 \mathrm{mg} / \mathrm{l}$ according to the World Health Organization (WHO)

660 guideline). In other words, optimal withdrawal policies can lead to a significant improvement in

661 the aquifer quantitative sustainability in the short term but to create the desired qualitative 662 condition, more time is needed. 


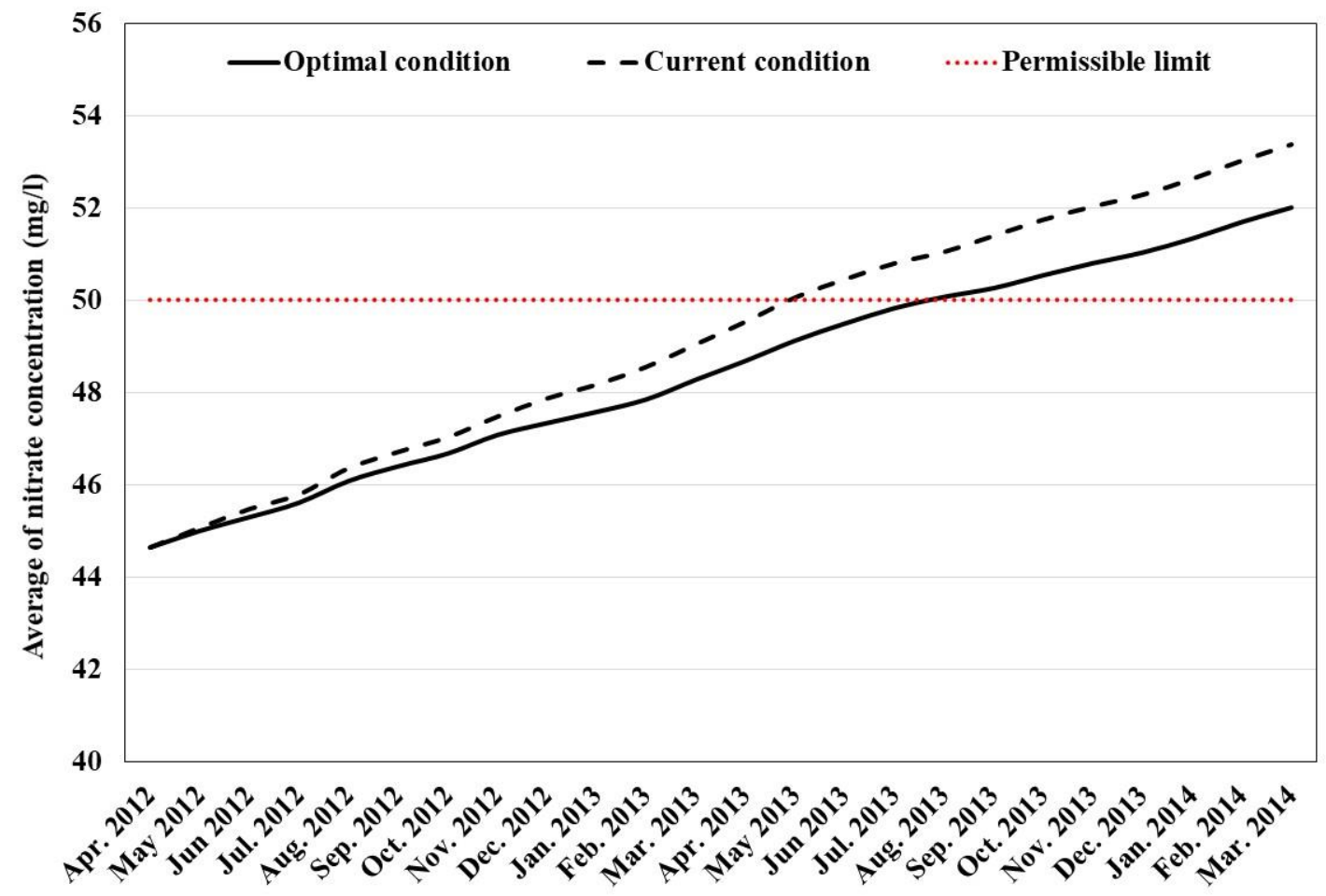

663

Fig. 15 Time series of nitrate concentration in Karaj Plain aquifer under optimal and current

666

667 Qualitative zoning of the nitrate parameter under the conditions of optimal allocation and 668 continuation of the current withdrawal process was drawn to evaluate the effectiveness of the 669 proposed approach in improving the qualitative aquifer conditions (Fig. 16). Investigation of 670 variation in nitrate concentration in the Karaj aquifer after applying the optimal operation policy

671 values shows that nitrate concentration in the northern, western and eastern parts of the aquifer has

672 been greatly reduced and it is in a more favorable condition. Continuation of optimal allocation 673 policies can lead to quantitative stability of aquifer short-term and improve the qualitative aquifer 674 status in terms of nitrate parameter. By calculating the levels covered by each of the nitrate 675 concentration ranges (based on the nitrate zoning map shown in Fig. 16), can be found that the 
zones with high concentrations of nitrate in the current conditions gradually replaced by zones

with lower concentrations of nitrate and the general qualitative conditions of the plain are moving

towards zones with low concentrations of nitrate. This is especially evident in areas with a large

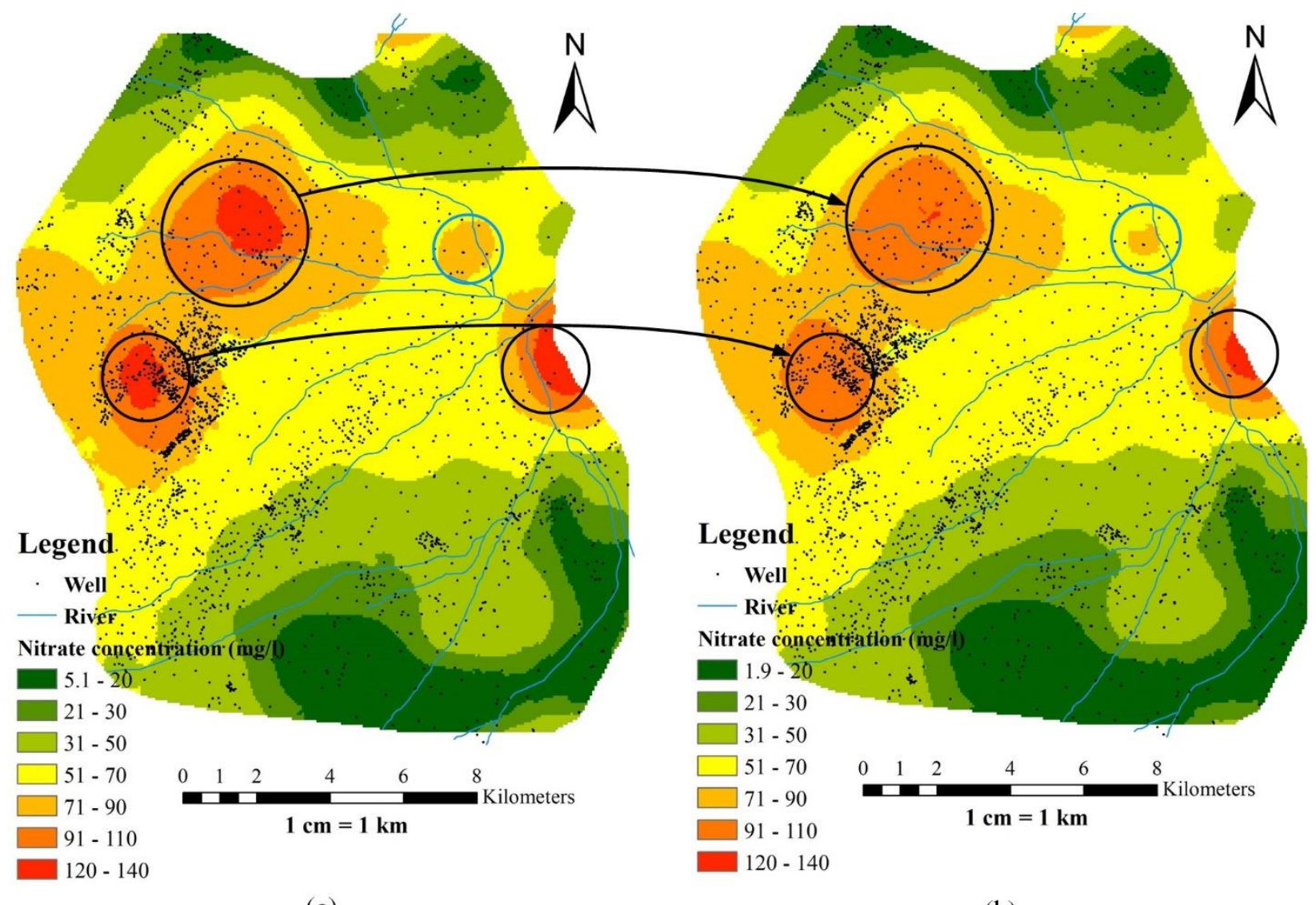

(a)

(b)

Fig. 16 Nitrate concentration distribution a) in current status b) after applying the proposed 
687 In order to compare the efficiency of the proposed approach in improving aquifer qualitative 688 conditions in terms of nitrate parameter, the time series of nitrate concentration for the two 689 different operating conditions (continuation of the current situation of aquifer operation and 690 applying proposed groundwater management model) were drawn in Figures 18 to 20. As shown 691 in these figures, the effectiveness of the developed structure in creating the qualitative stability of 692 the aquifer is quite evident. Recommendation to continue this process of optimal operation of wells 693 can be significantly effective in reducing the concentration of nitrate, due to the decreasing slope 694 of this parameter.

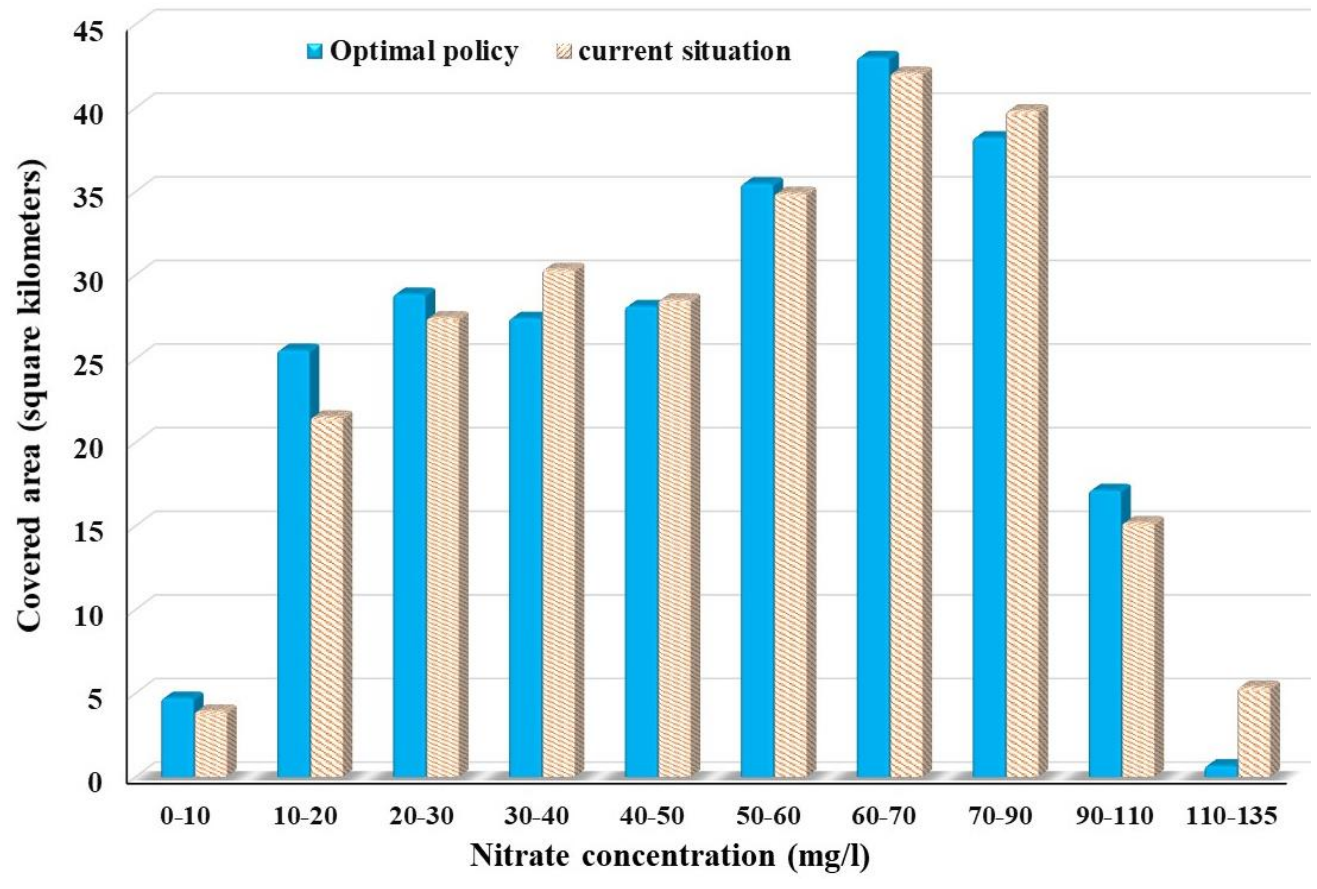

696 Fig. 17 The covered area of nitrate concentration with different ranges under optimal policy and 697 current situation (March 2014) 


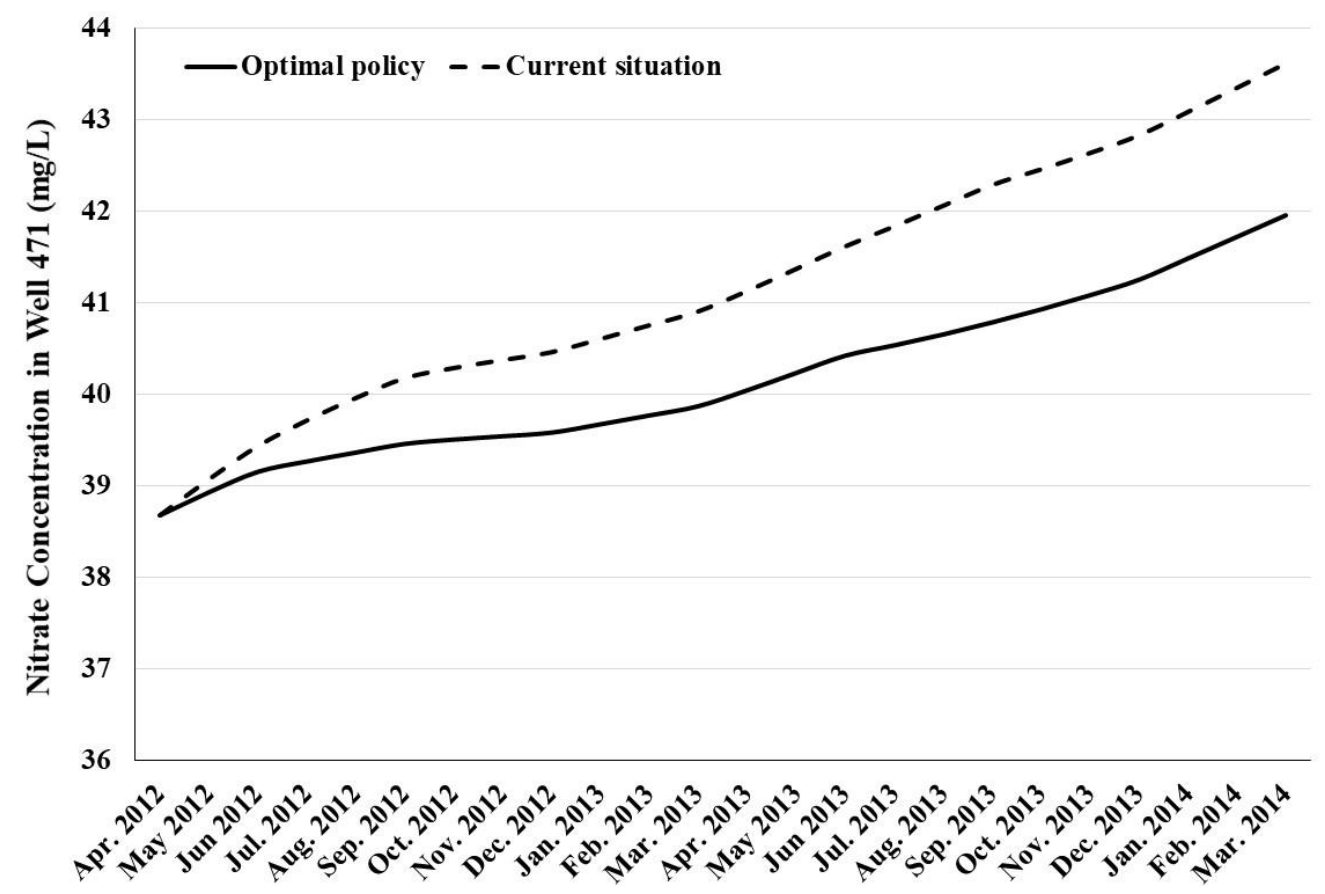

699 Fig. 18 Nitrate concentration time series in well number 471 under two different operating conditions

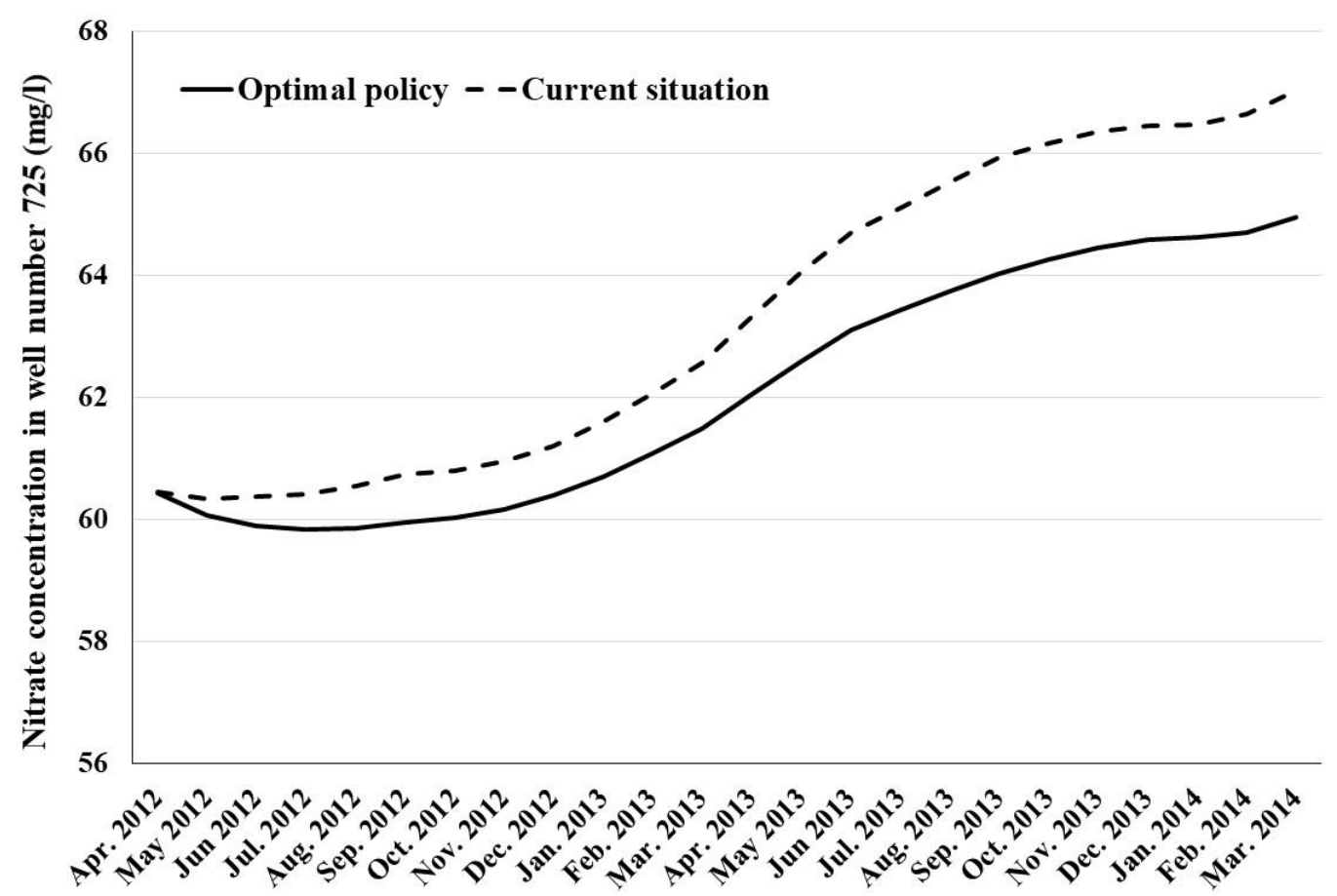

Fig. 19 Nitrate concentration time series in well number 725 under two different operating 


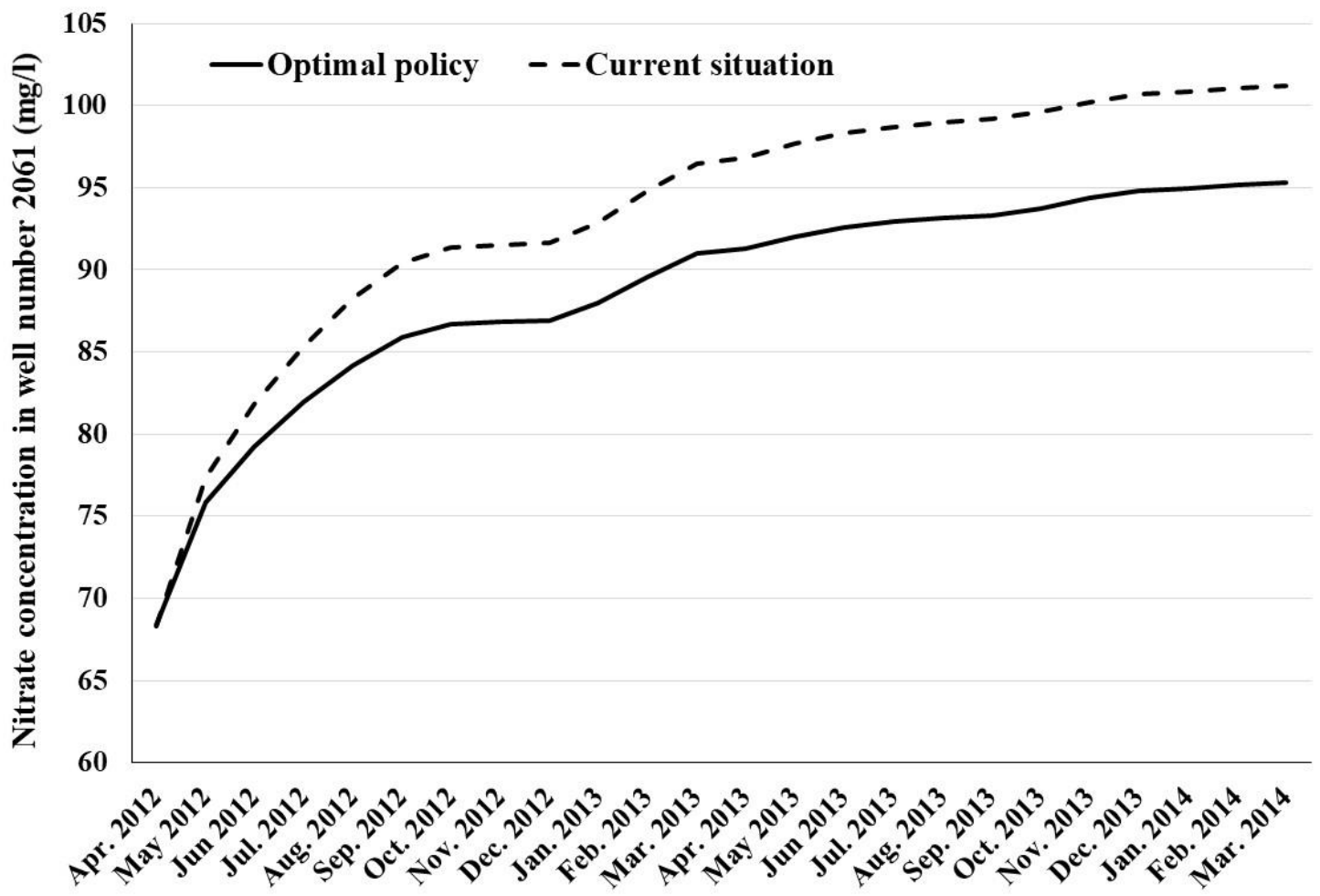

Fig. 20 Nitrate concentration time series in well number 2061 under two different operating conditions

\section{Conclusion}

708 This paper presented and developed a coupled optimization-simulation model for quantitative and 709 qualitative sustainable management of groundwater resources in an arid and semi-arid area (Karaj

710 plain aquifer). In the proposed model, three objective functions were formulated to minimize the 711 sum of drawdown of GWTL in drinking wells, minimize the sum of nitrate concentration in cells 712 containing operation wells, and minimize the sum of withdrawal rate from wells during planning 713 horizon. Due to appropriate accuracy and widespread use of the GMS model in investigating the 714 quantitative and qualitative behavior of the aquifer, code was prepared in MATLAB environment 715 with the aim of establishing link between this software and multi-objective optimization algorithm 716 (NSGA-II). In this code, the user will be able to change the status of the stresses in the groundwater 
717 system (like recharge and discharge) using a file with the h5 extension in the GMS model and

718 observe variation in GWTL and nitrate concentration after the implementation of GMS model.

719 After calibration and validation of GMS model under steady and unsteady conditions and its use

720 in multi-objective optimization model, the groundwater management model was implemented and

721 the optimal pareto-front of solutions (scenarios) between the objective functions was extracted. In

722 this study, seven MCDM methods were used to determine the rank of each solution and the BAM

723 method was applied to select the superior scenario.

724 Analysis of optimal allocation values of wells shows that in order to create sustainability in the 725 quantitative and qualitative status of the aquifer, it is necessary to reduce the total amount of 726 aquifer withdrawal from 471.55 MCM to 228.49 MCM over the planning horizon. This reduction 727 in abstraction has led to an average increase of $4.6 \mathrm{~m}$ in GWTL, which adds 95.3 MCM of water 728 to the static reservoir volume of the Karaj plain aquifer.

729 The results obtained from nitrate concentration variation after the implementation of the proposed 730 approach show that the area of aquifer zones with high nitrate concentration has decreased and the 731 quality status of the aquifer have improved. Accordingly, the northern, eastern and western parts 732 of the aquifer have experienced a decrease in nitrate concentration during the planning horizon. 733 For example, the area of lands with a nitrate concentration above $110 \mathrm{mg} / 1$ has decreased by $73487.5 \%$ and reached less than $0.67 \mathrm{~km}^{2}$.

735 Examination of the results obtained from the application of the proposed approach in the 736 quantitative and qualitative management of the aquifer shows that the developed structure of the 737 simulation-optimization model has a high performance in improving the quantitative and 738 qualitative status of the groundwater system. In fact, the simultaneous application of the NSGA-II 
and GMS models, and MCDM methods using the developed MATLAB code can be successfully

740 used to manage complex aquifer systems that have significant operation resources.

742 Acknowledgements

743 The authors of this article would like to thank the Alborz Regional Water Company for providing 744 quantitative and qualitative groundwater data on the Karaj plain aquifer.

\section{Ethical Approval}

747 This article does not contain any studies with human participants or animals performed by any of 748 the authors.

\section{Consent to Participate}

$750 \quad$ Not Applicable

751 Consent to Publish

752 Not Applicable

753 Authors Contributions

754 Mahmoud Mohammad Rezapour Tabari: Conceptualization, Supervision, Methodology, Data

755 acquisition, Writing- Original draft preparation

756 Mehdi Eilbeigi: Conceptualization, Methodology, Visualization, Editing of manuscript

757 Manouchehr chitsazan: Methodology, Supervision, Editing of manuscript

$758 \quad$ Funding

759 Not Applicable

$760 \quad$ Competing Interests

761 The authors declare that they have no conflicts of interest. 


\section{Availability of data and materials}

Data and material would be made available on request.

\section{References}

Ahlfeld, D.P., Pinder, G.F., 1992. A fast and accurate method for solving subsurface contaminant transport problems with a single uncertain parameter. Adv. Water Resour. 15, 143-150.

Alizadeh, M.R., Nikoo, M.R., Rakhshandehroo, G.R., 2017. Hydro-environmental management of groundwater resources: A fuzzy-based multi-objective compromise approach. Journal of hydrology. 551, 540-554.

Ayvaz, M.T., 2010. A linked simulation-optimization model for solving the unknown groundwater pollution source identification problems. Journal of Contaminant Hydrology. 117(1), 46-59.

Ayvaz, M.T., 2016. A hybrid simulation-optimization approach for solving the areal groundwater pollution source identification problems. Journal of Hydrology, 538, 161-176.

Ayvaz, M.T., Karahan, H., 2008. A simulation/optimization model for the identification of unknown groundwater well locations and pumping rates. J. Hydrol. 357, 76-92.

Banihabib, M.E., Tabari, M.M.R., Mohammad Rezapour Tabari, M., 2017. Development of integrated multi-objective strategy for reallocation of agricultural water. Iran-Water Resources Research. 13(1), 38-52 (in Persian).

Banihabib, M.E., Tabari, M.M.R., Mohammad Rezapour Tabari, M., 2019. Development of a Fuzzy Multi-Objective Heuristic Model for Optimum Water Allocation. Water Resources Management. 33, 3673-3689. 
Chitsazan, M., Tabari, M.M.R., Eilbeigi M., 2017. Analysis of temporal and spatial variations in groundwater nitrate and development of its pollution plume: a case study in Karaj aquifer. Environmental Earth Sciences. 76, 391.

Ebraheem, A.M., Garamoon, H.K., Riad, S., Wycisk, P., El, Seif, Nasr, A.M., 2003. Numerical modeling of groundwater resource management options in the East Oweinat area, SW Egypt. Environmental Geology. 44(4), 433-447.

Elci, A., Tamer Ayvaz, M., 2014. Differential-Evolution algorithm based optimization for the site selection of groundwater production wells with the consideration of the vulnerability concept. Journal of Hydrology. 511, 736-749.

Esteban, E., Dinar, A., 2013. Cooperative management of groundwater resources in the presence of environmental externalities. Environ Resour Econ. 54(3), 443-469.

Farhadi, S., Nikoo, M.R., Rakhshandehroo, G.R., Akhbari, M., Alizadeh, M.R., 2016. An agentbased-Nash modeling framework for sustainable groundwater management: a case study. Agric Water Management. 177, 348-358.

GAD, M.I., Khalaf, S., 2013. Application of sharing genetic algorithm for optimization of groundwater management problems in Wadi El-Farigh, Egypt. Applied Water Science. 3, $701-716$.

Gaur, S., Chahar, B.R., Graillot, D. 2011. Analytic elements method and particle swarm optimization based simulation-optimization model for groundwater management. Journal of Hydrology. 402, 217-227.

Ghaseminejad, A., Shourian, M., 2019. A simulation-optimization approach for optimal design of groundwater withdrawal wells' location and pumping rate considering desalination constraints. Environmental Earth Sciences. 78, 270. 
Iran Water Resources Management Corporation, 2017. Evaluation of groundwater resources of Iran by the end of 2015-2016 water year. Office of Water Resources Research, Groundwater group (In Persian).

Karamouz, M., Tabari, M.M.R., Kerachian, R., 2007. Application of genetic algorithms and artificial neural networks in conjunctive use of surface and groundwater resources. Water International. 32(1), 163-176.

Karamouz, M., Tabari, M.M.R., Kerachian, R., Zahraie, B., 2005. Conjunctive Use of Surface and Groundwater Resources with Emphasis on Water Quality, Proceedings of World Water and Environmental Resources Congress, Anchorage, Alaska, May 15-19, 2005.

Kazemzadeh-Parsi, M.J., Daneshmand, F., Ahmadfard, M.A., Adamowski, J., 2015. Optimal remediation design of unconfined contaminated aquifers based on the finite element method and a modified firefly algorithm. Water Resources Management. 29(8), 2895-2912.

Luo, Q., Wu, J., Yang, Y., Qian, J., Wu, J., 2016. Multi-objective optimization of long-term groundwater monitoring network design using a probabilistic Pareto genetic algorithm under uncertainty. Journal of Hydrology. 534, 352-363.

Majumder, P., Eldho, T.I., 2015. An optimal strategy for groundwater remediation by coupling Groundwater Modeling System (GMS) and Particle Swarm Optimization (PSO). In 47th IWWA Annual Convention, 1-8.

Majumder, P., Eldho, T.I., 2016. A New Groundwater Management Model by Coupling Analytic Element Method and Reverse Particle Tracking with Cat Swarm Optimization. Water Resources Management. 30, 1953-1972. 
Norouzi Khatiri, K., Niksokhan, M.H., Sarang, A., 2020. Coupled Simulation-Optimization Model for the Management of Groundwater Resources by Considering Uncertainty and Conflict Resolution. Water Resources Management. https://doi.org/10.1007/s11269-020-02637-X

Pena-Haro, S., Pulido-Velazquez, M., Llopis-Albert, C., 2011. Stochastic hydro-economic modeling for optimal management of agricultural groundwater nitrate pollution under hydraulic conductivity uncertainty. Environmental Modelling \& Software. 26(8), 999-1008.

Pena-Haro, S., Pulido-Velazquez, M., Sahuquillo, A., 2009. A hydro-economic modelling framework for optimal management of groundwater nitrate pollution from agriculture. Journal of Hydrology. 373, 193-203.

Rashid, H., Al-Shukri, H., Mahdi, H., 2014 Optimal management of groundwater pumping of the cache critical groundwater area, Arkansas. Applied Water Science. 5, 209-219.

Rejani, R., Jha, M.K., Panda, S.N., 2009. Simulation-Optimization Modelling for Sustainable Groundwater Management in a Coastal Basin of Orissa, India. Water Resources Management. $23,235-263$.

Rogers, L.L., Dowla, F.U., 1994. Optimization of groundwater remediation using artificial neural networks with parallel solute transport modeling. Water Resources Research. 30(2), 457-481.

Sabzzadeh, I., Shourian, M., 2020. Maximizing crops yield net benefit in a groundwater-irrigated plain constrained to aquifer stable depletion using a coupled PSO-SWATMODFLOW hydroagronomic model. Journal of Cleaner Production. 262, 121349.

Sabzzadeh, S., Ahmadi, A., 2019. Non-cooperative stability assessments of groundwater resources management based on the tradeoff between the economy and the environment. Journal of Hydrology. 578, 124075. 
Safavi, H.R., Darzi, F., Mariño, M.A., 2010. Simulation-Optimization Modeling of Conjunctive Use of Surface Water and Groundwater. Water Resources Management. 24, 1965-1988.

Salcedo-Sa'nchez, E.R., Vicenta Esteller, M., Garrido Hoyos, S.E., Martı'nez-Morales, M., 2013. Groundwater optimization model for sustainable management of the Valley of Puebla aquifer, Mexico. Environmental Earth Science. 70, 337-351.

Sedki, A., Ouazar, D., 2011. Simulation-Optimization Modeling for Sustainable Groundwater Development: A Moroccan Coastal Aquifer Case Study. Water Resources Management. 25, $2855-2875$.

Sreekanth, J., Moore, C., Wolf, L., 2015. Estimation of Optimal Groundwater Substitution Volumes Using a Distributed Parameter Groundwater Model and Prediction Uncertainty Analysis. Water Resources Management. 29, 3663-3679.

Tabari, M.M.R., 2015. Conjunctive Use Management under Uncertainty Conditions in Aquifer Parameters. Water Resources Management, 29(8), 2967-2986.

Tabari, M.M.R., Azadani, M.N., Kamgar, R., 2020. Development of operation multi-objective model of dam reservoir under conditions of temperature variation and loading using NSGAII and DANN models: a case study of Karaj/Amir Kabir dam. Soft Computing. 24, 1246912499.

Tabari, M.M.R., Soltani, J., 2013. Multi-Objective Optimal Model for Conjunctive Use Management Using SGAs and NSGA-II Models. Water Resources Management. 27(1), 3753.

Tabari, M.M.R., Yazdi, A., 2014. Conjunctive use of surface and groundwater with inter-basin transfer approach: case study Piranshahr. Water resources management. 28(7), 1887-1906. 
872 Wang, M., Zheng, C., 1994. Ground water management optimization using genetic algorithms and 873 simulated annealing: formulation and comparison. Journal of the American water resources $874 \quad$ association. 34(3), 519-530.

875 Xiang, Z., Bailey, R.T., Nozari, S., Husain, Z., Kisekka, I., Sharda, V., Gowda, P., 2020. DSSAT876 MODFLOW: A new modeling framework for exploring groundwater conservation strategies 877 in irrigated areas. Agricultural Water Management. 232. 106033.

878 Zhang, Y., Gong, H., Gu, Z., Wang, R., Li, X., Zhao, W., 2014. Characterization of land 879 subsidence induced by groundwater withdrawals in the plain of Beijing city, 880 ChinaCaracterisation de la subsidence induite par les prelevements d'eaux souterraines dans 881 la plaine de Pekin, Chine Caracterizacion de la subsidencia del. Hydrogeol. J. 22, 397-409.

882 Zheng, C., Wang, P.P., 2002. A field demonstration of the simulation optimization approach for 883 remediation system design. Ground Water. 40(3), 258-266. 